\title{
FUERZAS ARMADAS-SOCIEDAD: DEL MUTUO AISLAMIENTO A LA PROGRESIVA INTEGRACION
}

1. Ejército y sociedad. El tradicional aislamiento de los Ejércitos

Ha venido constituyendo lugar común en el análisis de los Ejércitos la referencia a su falta de imbricación social, esto es, al aislamiento de los militares respecto de su entorno social ${ }^{1}$. Busquets considera tal circunstancia como una constante común de todas las sociedades en las que aparece el Ejército permanente, sustituyendo al inicial sistema de milicias o de ciudadanos que toman las armas en casos de peligro ${ }^{2}$.

Es evidente que en la actualidad los Gobiernos democráticos se esfuerzan en aumentar la integración del Ejército y el pueblo, pero no es menos patente que, en mayor o menor grado, el aislamiento sigue existiendo en todos los países occidentales ${ }^{3}$; es un fenómeno universal, bien que hoy venga atempera-

${ }^{1}$ Gwyn Harries-Jenkins y Charles C. Moskos, Jr. (en Las Fuerzas Armadas y la Sociedad, Alianza Editorial, Madrid, 1984, p. 45), llegan a separar los estudios sociológicos de los fenómenos militares en dos grupos, según se encuentren interesados en el análisis del Ejército como organización diferenciada y cerrada en sí misma o partan de la premisa de que los sectores militares y civiles de la sociedad interactúan y poseen fines comunes.

2 Julio BusqueTs, El militar de carrera en España, Editorial Ariel, 1. ${ }^{\mathrm{a}}$ ed. (existen dos ediciones precedentes, de 1967 y 1971, publicadas en la Colección Demos), Barcelona, 1984, p. 209.

${ }^{3}$ En análogo sentido, Julio Busquets, El militar..., op. cit., p. 210. 
do por una serie de circunstancias a las que nos iremos refiriendo más adelante.

La doctrina se ha venido haciendo eco de modo sistemático de este aislamiento. Recordemos al efecto que ya Vigny hablaba ${ }^{4}$ de que el Ejército es una nación en la Nación, y en otro pasaje de su Servidumbre y grandeza militar se referirá Vigny a «lo que aún queda de atrasado y de bárbaro en la organización modernísima de nuestros ejércitos permanentes, donde el hombre de guerra está aislado del ciudadano, donde es desdichado y feroz, porque se da cuenta de su mala y absurda condición» ${ }^{5}$, juicio que motivará la apasionada réplica de Vigón ${ }^{6}$, para quien el aislamiento al que se refiere el conde de Vigny, que las más de las veces, si no todas, ha venido determinado por un recelo sin justificación que los Ejércitos han solido percibir en torno suyo, no parece que haya engendrado, sin embargo, irremediables desdichas ni desarrollado de un modo especial la ferocidad. Pero es seguro, concluye Vigón, que los Ejércitos preferirían siempre una convivencia confiada a la recelosa caridad que la absoluta incomprensión de Vigny ofrece.

Janowitz ${ }^{7}$ se ha referido a este aislamiento, aludiendo en diversos pasajes de su obra al carácter cerrado de la comunidad militar: «The military community is a relatively clased community where professional and residential life have been completely intermingled»; esa interrelación que tiene lugar entre la vida profesional y la que podríamos considerar como vida familiar o privada coadyuva sensiblemente a fomentar el carácter cerrado de la comunidad castrense; no en vano ha sido la vida familiar la que se ha visto moldeada por los requerimientos de la profesión militar ${ }^{8}$. Y, al propio tiempo, la existencia de un estilo de vida militar, a la par que cohesiona internamente a la comunidad militar, frustra su integración con la sociedad civil. «If the military style of life strives to produce an internally cohesive community, at the same time, it thwarts social integration with civilian society»".

Desde el punto de partida de las consideraciones que preceden, no parece desacertado el mantener, con Cardona ${ }^{10}$, que los Ejércitos permanentes tienden a dar sentido a la totalidad de la vida. Puede hablarse más de condición militar que de profesión militar.

${ }^{4}$ Alfredo DE VIGNY, Servidumbre y grandeza militar, 3." ed., Espasa-Calpe, Madrid, 1962 , p. 16.

${ }^{5}$ Ibidem, p. 9.

- Jorge VIGÓN, «El espíritu militar español», en su obra Estampa de capitanes. El espíritu militar español, publicadas de modo conjunto por Ediciones Ejército, Madrid, 1979, p. 282.

${ }_{7}$ Morris Janowitz, The Professional Soldier. A social and political portrait, The Free Press Paperback, Macmillan, Londres, $4 .^{.}$impr., 1968, p. 177.

${ }_{B}$ Morris Janowitz, The Professional Soldier, op. cit., p. 187.

9 Ibidem, p. 204.

${ }^{10}$ Gabriel CaRdona, El poder militar en la España contemporánea hasta la guerra civil, Siglo XXI de España, Editores, Madrid, 1983, p. 22. El aislamiento, la endogamia, la moral profesional, los sentimientos de solidaridad y compañerismo - añade Cardona - llevan a la institución hacia el automatismo y la autosuficiencia frente a la diferente sociedad exterior. 
El aislamiento a que nos estamos refiriendo no es, por lo demás, rasgo exclusivo de los Ejércitos, sino, por el contrario, de cualquier organización social compleja; como se admite de modo general ${ }^{11}$, las organizaciones sociales complejas tienden a aislarse relativamente del entorno para afirmar así su singularidad, y emplean el secreto como un recurso en su relación con los otros elementos del entorno.

Razones políticas de supervivencia explican la negativa de este tipo de organizaciones complejas, y en cierto modo autosuficientes, a abrirse al entorno circundante. Los Ejércitos, se subraya ${ }^{12}$, como cualquier organización social, tienden a minimizar la incertidumbre a través del control de su contexto. Por ello, gran parte de sus actividades se dirigen, a semejanza de otras organizaciones, a dominar y reducir al mínimo la incertidumbre proveniente del entorno, captando sistemáticamente la mayor cantidad de información considerada de interés para los fines organizativos.

Por otra parte, no es un hecho nuevo el que amplios sectores de la sociedad rechacen los valores y modos de conducta que tienen su punto de origen en los Ejércitos; a este respecto, son reveladoras las palabras del general Díez Alegría ${ }^{13}$ : «En lo social —afirma el ilustre militar y académico-, el oficial suele tropezar con una incomprensión total de sus problemas, no sólo por parte de los dirigentes, sino incluso de la sociedad como un todo. En las condiciones actuales de vida, en que los valores morales bajan de cotización a la vez que suben los materiales, la categoría social militar desciende inexorablemente y su vida se hace cada vez más difícil. El militar llega a sentirse como un extranjero en su propia Patria, donde nadie entiende sus razones ni comparte sus inquietudes. $Y$ esto no es nuevo, puesto que ya al mariscal de Sajonia se le atribuía la frase "en nosotros no se piensa más que cuando llueve".»

Sucede, tal y como ha significado Perlmutter ${ }^{14}$, que la rápida expansión de la tecnología industrial ha creado un sistema de valores en el cual la productividad y las ganancias materiales son las metas principales. En tal contexto, los contrastes entre el militar, cuya productividad material no es visible, y el ciudadano superproductor son enormemente grandes. En una situación de ese tipo, en la que el militar se ve apartado de los valores predominantes, puede reaccionar defensivamente con una afirmación más honda de las pecu-

${ }^{11}$ Cfr., al efecto, Anthony JAY, Management and Macbiavelli. An Inquiry into the Politics of Corporate Life, Holt, Rinehart y Winston, Nueva York, 1968. Cit. por Rafael Bañón y José A. Olmeda, «El estudio de las Fuerzas Armadas», en Bañón y Olmeda (comps.), La institución militar en el Estado contemporáneo, Alianza Editorial, Madrid, 1985 , pp. 13 y ss.; en concreto, p. 16.

${ }^{12}$ Rafael Bañón y José Antonio Olmeda, Análisis social y Fuerzas Armadas, ponencia presentada al II Congreso Nacional de Sociología, Santander, 1984, p. 6.

${ }^{13}$ Manuel Díez Alegría, Ejército y Sociedad, Alianza Editorial, Madrid, 1972, p. 55.

${ }^{14}$ Amos Perlmutter, The Military and Politics in modern times. On Professionals, Praetorians and Revolutionary Soldiers, Yale University Press, New Haven y Londres, 1977, p. 39. 
liaridades que la sociedad exige de él. De este modo puede llegar a aislarse a sí mismo de la sociedad a la que debe defender.

A la vista de cuanto antecede, no parece en exceso aventurado establecer una conexión entre el grado de integración social de los profesionales de la Milicia y la estima que su propia profesión suscita entre el resto de los ciudadanos. Así lo subraya Perlmutter: «the feeling of the professional soldier toward his state will, of course, be partly determined by the esteem that his profession commands in relation to others» ${ }^{15}$.

A la vista de cuanto se ha puesto de relieve, no puede extrañar la consideración, constatada por la doctrina ${ }^{16}$, de que los militares forman un grupo social lo suficientemente compacto, cerrado y autosuficiente como para que pueda llegarse a hablar de la «sociedad militar» en contraposición a la «sociedad civil».

Si a todo ello unimos el que en numerosas ocasiones los militares, creyéndose en posesión de la única y absoluta verdad ${ }^{17}$, no se han molestado en explicar sus posicionamientos a esa «sociedad civil», o lo han hecho mal, o han exagerado los planteamientos ${ }^{18}$, o, más aún, partiendo de la premisa -que, desde luego, puede ser aceptada por quienes no se integran en el grupo social militar- de que los Ejércitos constituyen una institución básica de la sociedad ${ }^{19}$, han tratado de imponer a sectores sociales ajenos o extraños a la institución castrense unos conceptos o valores que son específicos de su profesión, como, por ejemplo, exigir que la sociedad en su conjunto tenga como norte los valores e ideales que inspiran a la Milicia; si tenemos presentes estas circunstancias - conjuntamente con las contempladas en un momento anterior-, no debe causar asombro la constatación, que revela nuestra historia contemporánea, de cómo en ciertos momentos «sociedad civil» y «sociedad militar» han sido algo así como dos entes recelosos cuyas interrelaciones han venido presididas por la mutua desconfianza.

En nuestros días, afortunadamente, la situación descrita parece tender a aminorarse. Como al efecto se ha puesto de relieve ${ }^{20}$, hoy es evidente que el coto cerrado de la Milicia tiende a limitarse con muros o alambradas menos

is Amos Perlmutter, The Military and Politics..., op. cit., p. 39.

${ }^{16}$ Así, por ejemplo, Jesús Martínez Paricio, Para conocer a nuestros militares, Tecnos, Madrid, 1983 , p. 46.

${ }_{17}$ Francisco López dE SePúlveda, «Sociedad y Fuerzas Armadas» (II), en Ejército (Revista de las Armas y Servicios), núm. 505, febrero 1982, pp. 17 y ss.; en concreto, p. 20.

${ }_{18} \mathrm{Tal}$ es el caso de Jorge Vigón Suerodíaz (en Milicia y Política, Instituto de Estudios Políticos, Madrid, 1947 , p. 389), para quien el Ejército es siempre la única armadura sólida de un orden social cualquiera. Por eso, cuando no se trata más que de subvertirlo, el antimilitarismo es el más eficaz de los resortes que pueden ser puestos en juego.

${ }_{19}$ En un editorial de la revista Reconquista (núm. 347, febrero 1979 , p. 3) se reconocen como «instituciones básicas de nuestra civilización» la Iglesia, la Familia, los Ejércitos y la Justicia.

${ }^{20}$ Carlos Martínez de Campos y Serrano, «Evolución de la Defensa Nacional», en Arbor (Revista General de Investigación y Cultura), tomo LXXVII, núm. 300, diciembre 1970 , pp. 17 y ss.; en concreto, p. 18. 
altos y menos seguros que todos los antiguos. $Y$, a nuestro modo de ver, también parece algo patente que la sociedad civil, por así llamarla, ha perdido buena parte de sus tradicionales recelos frente a la institución militar.

Ello no obstante, el fenómeno del aislamiento - mitigado, desde luegosigue teniendo cierta vigencia en las sociedades de nuestros días. Por lo que se refiere a nuestro país, no parece en modo alguno que ni tan siquiera en sectores militares significativos puedan hallar eco consideraciones como la de que aunque los oficiales ya no son aristócratas, en el viejo concepto del orgulloso clasismo, siguen sintiéndose miembros de una "aristocracia del espíritu» que rechaza como inferiores las aspiraciones vulgares con que el prosaico vivir tiende a encadenarnos cada día ${ }^{21}$; una manifestación de este tipo, aparte de trasnochada, carece de toda posible verificación empírica, a nuestro modo de ver.

Sin embargo, la realidad nos muestra una serie de circunstancias que se conjugan para generar un más o menos acusado sentido de diferenciación frente a las aspiraciones y mentalidades civiles, en el bien entendido de que al no poderse predeterminar una específica «mentalidad civil», sino una pluralidad de aspiraciones, idealizaciones y mentalidades, las diferencias precitadas aumentarán o disminuirán según los grupos sociales con los que se establezca la comparación.

En todo caso, diversas circunstancias — como acabamos de señalar- siguen propiciando ese llamémosle «espíritu diferencial»; recordemos (además de las ya aducidas con anterioridad, de carácter más genérico) algunas de ellas: a) el profundo sentido de hermandad de los miembros de la Milicia; b) su «espíritu de cuerpo», entendido como la solidaridad basada en la lealtad recíproca, que produce casi automáticamente la igualdad de fines, cuyo logro requiere un afán común, trabado y coherente $\left.{ }^{22} ; c\right)$ su propio sistema de cosmovisión de naturaleza mítico-simbólica, esto es, asentado en símbolos, mitos y tradiciones; d) su misma personalidad etnocéntrica, que, según Paricio $^{23}$, supone que el militar va a mostrarse rígido en la aceptación de lo culturalmente no-semejante, rechazando todo lo que suponga diversidad y heterogeneidad, y $e$ ) por último, el propio espíritu militar que anima a los miembros de las Fuerzas Armadas, que ha sido concebido - entre otros muchos intentos de definirlo y perfilarlo- como «esa tensión permanente en que se subliman los mejores valores del hombre» ${ }^{24} \mathrm{y}$ respecto del cual se ha advertido que, por ser muy fluido, necesita llevarse en los bidones de la disciplina ${ }^{25}$. Y, por

2 Manuel Cabeza Cala horra, La ideología militar boy, Editora Nacional, Madrid, 1972, pp. 201-202.

22 Emilio Romero Salgado, Temas de Moral Militar, Imprenta del Ministerio de Marina, Madrid, 1962 , p. 305.

${ }_{23}$ Jesús Martínez Paricio, Para conocer..., op. cit., p. 126.

24 Emilio Romero Salgado, Temas de Moral Militar, op. cit., p. 165.

${ }_{25}$ Pedro DE CóRDoba, «La letra y el espíritu», en la revista Reconquista, núm. 346. enero 1979 , p. 48. 
encima de todas estas circunstancias, como advierte Huntington ${ }^{26}$, lo que distingue al militar, en cuanto profesional, de otros profesionales «civiles» es el sentido de su misión, de la historia y de la nación. Precisamente, las contradicciones entre las intenciones, fines y designios de los militares y los valores de la sociedad crean, a juicio de Harries-Jenkins ${ }^{27}$, uno de los más complejos problemas de acoplamiento entre el sistema militar y el sistema político.

Si se nos permite el excursus, debemos referirnos a continuación a una cuestión de verdadero interés, bien que relacionada tan sólo tangencialmente con el tema que nos ocupa; se trata de si la homogeneidad de la institución militar permite hablar, efectivamente, de una «sociedad militar» frente a una «sociedad civil», o si, por contra, dentro de la institución armada existen orientaciones tan dispares que no permiten hablar de una peculiar «mentalidad militar»y, en consecuencia, impiden analizar si las relaciones con la sociedad civil son de integración o aislamiento.

En España, y en directa referencia a nuestros Ejércitos, se ha puesto de relieve ${ }^{28}$ que en ellos siempre ha habido diferencias, y no sólo con el resto del país, sino entre muchos de sus miembros; a nuestro juicio, la existencia de diferencias individuales no obsta para que descalifiquemos sin más la validez de un grado de cohesión u homogeneidad que se superponga a las normales discrepancias individuales en todo colectivo social. Desde este punto de vista, no podemos estar de acuerdo con la consideración de Cardona ${ }^{29}$ de que, aunque los Ejércitos suelen tener una apariencia oficial y monolítica (la que conviene al poder), son fruto de largas acumulaciones históricas y, tras la pantalla de los uniformes, subyacen grupos diferentes, antagónicos incluso. A nuestro modo de ver, es obvio que entre los diferentes Ejércitos de un mismo país $\mathrm{y}$, dentro de ellos, entre las distintas armas y, aun dentro de éstas, entre las varias escalas existen diferencias que, incluso, pueden llegar a ser notorias en un momento dado, sin que en ningún supuesto pueda hablarse de antagonismos irreversibles; ahora bien, esas discrepancias no son sino las mismas (bien que aminoradas), o por lo menos semejantes, a las que podrían detectarse si se procediera a la disección minuciosa de cualquier otro grupo social.

Es preciso al respecto no olvidar que los Ejércitos vienen caracterizados por un específico grado de cohesión que, desde luego, no se da con la intensidad que en ellos en ninguna otra institución social. $Y$ es que, como subraya

${ }^{26}$ Samuel P. Huntington, «The rise of the military profession in western society», en Amos Perlmutter y Valerie Plave Bennet (eds.), The Political influence of the Military. A comparative reader, Yale University Press, New Haven y Londres, 1980, pp. 46 y ss.; en concreto, p. 47.

${ }^{27}$ Gwyn Harries-Jenkins, «Armed Forces and the Welfare State», en Morris JanowITz (ed.), Civil-Military relations. Regional perspectives, Sage Publications, Beverly HillsLondres, 1981, pp. 231 y ss.; en concreto, p. 236.

${ }^{28}$ Carlos Fernández, Los militares en la transición política, 2." ed., Argos Vergara, Barcelona, 1982, p. 11.

${ }^{29}$ Gabriel Cardona, El poder militar..., op. cit., p. 1. 
Andreski ${ }^{30}$, un Ejército constituido por una amplia multitud de soldados, independientes unos de otros, no sería tal Ejército. La cohesión, indica en análoga dirección Janowitz ${ }^{31}$ —entendiendo por tal «the feeling of group solidarity and the capacity for collective action»-, es un aspecto esencial de la organización interna de la profesión militar. De otro lado, esa cohesión no puede considerarse emanada del puro ejercicio de la autoridad y de la disciplina, sino que obedece en su ser más profundo a la comunión de sentimientos en torno a unos mismos ideales, principios y valores de índole superior. Además, el servicio en las Fuerzas Armadas, como advierte Gutteridge ${ }^{32}$, implica disciplina, y la disciplina crea cohesión y, quizá, un sentido real de espíritu de cuerpo ${ }^{33}$.

En definitiva, es cierto que, como cualquier otro grupo social, el militar no se nos presenta como un bloque absolutamente monolítico y unidireccional en cuanto a las constantes esenciales de su pensamiento; ahora bien, una serie de factores, entre los que hay que incluir una escala de valores con un perfil diferencial característico ${ }^{34}$, propician que el rasgo de la homogeneidad se imponga al de la diversidad en lo que a la institución militar en su conjunto se refiere, siendo un dato que refuerza esta apreciación el de que en los Ejércitos no son significativas las diferencias de pensamiento entre los diversos bloques generacionales, rasgo éste que no suele producirse en otros grupos sociales ${ }^{35}$. Por todo ello, creemos que bien puede concluirse afirmando, con Paricio ${ }^{36}$, que los miembros de la institución militar «son varios y, sin embargo, todos son uno».

Hasta aquí hemos apuntado distintas circunstancias que pueden coadyuvar a la génesis o acentuamiento del sentido de diferenciación del grupo social militar; sin embargo, y junto a ellas, podemos detectar otros factores que inciden de modo significativo en el aislamiento social del grupo, que, por lo demás, no sólo es un fermento de debilidad de la propia cohesión social, sino

30 Stanislav ANDreski, Military Organization and Society, Routledge \& Kegan Paul, Londres, $2 .^{2}$ ed., 1968 , p. 121.

${ }^{31}$ Morris JANOWITZ, The Military in the political development of new nations. An essay in comparative analysis, The University of Chicago Press, Chicago, 1964, p. 67.

${ }^{32}$ William GutTERIDGe, Military Institutions and power in the new States, Pall Mall Press, Londres y Dunmow, 1964, p. 47.

${ }^{33}$ Para Julian Lider (en Military Theory. Concept, structure, problems, Gower Publishing Company Limited, Aldershot, Inglaterra, 1983, p. 37), la jerarquía, la disciplina y la cohesión constituyen un tríptico entre cuyos elementos se establece una estrechísima vinculación.

${ }^{34}$ Cfr., al respecto, Francisco Fernández Segado, «El perfil diferencial de la escala de valores de la Institución Militar», en Revista de Estudios Políticos, núm. 51, mayojunio 1986, pp. 79-126.

${ }^{35}$ Ello no obsta para reconocer que por mor de determinadas circunstancias históricas, en España, algunas generaciones de militares han venido connotadas por rasgos específicos que les han dado un sesgo particularizado en su modo de pensar y sentir; tal sería el caso de los militares de Marruecos o los de la guerra civil.

${ }^{36}$ Jesús M. PARIcio, Para conocer..., op. cit., cap. $1^{\circ}$, pp. 15 y ss. 
que, como sostiene Janowitz ${ }^{37}$, no supone en modo alguno una ventaja para la misma institución castrense. Busquets se ha referido detenidamente a aquellos factores, a los que vamos finalmente a aludir, significando que están contemplados con relación específica a nuestros Ejércitos.

En la primera edición de su obra ${ }^{38}$, el referido autor enumera seis factores diferenciados: a) un elevado índice de autorreclutamiento; $b$ ) un elevado índice de endogamia social, que probablemente sobrepase el 50 por 100 , y que comporta que la mayoría de los militares se casen con hijas de compañeros de profesión; c) una educación distinta a la que recibe el resto de la sociedad, al menos en los centros de enseñanza superior, fruto del sistema de enseñanza militar que se imparte en las Academias Militares; $d$ ) un trabajo en el cuartel, unidad o dependencia respectiva que, por lo general, se realiza sin contacto con el público; e) la existencia de viviendas militares en las que reside un alto número de miembros de la institución, que de este modo malogra otra posibilidad de convivencia con el resto de la sociedad, y $f$ ) una vida intelectual escasa, que refuerza posiblemente los criterios, ideologías y sistemas de valores de los miembros de la Milicia.

En la última edición de su obra, Busquets añade otras dos nuevas causas motivadoras del aislamiento ${ }^{39}$ : de un lado, la realización de muchas actividades de la vida separados del resto de la sociedad, lo cual no es sino la resultante obligada de la precariedad económica en que el militar ha vivido tantos años $y$, en buena medida, aún sigue viviendo; $y$, de otro, lo que podríamos llamar el desarraigo territorial, consecuencia de los frecuentes traslados profesionales que impiden el arraigo local.

De los ocho factores precedentemente citados, a nuestro modo de ver, algunos de ellos, aisladamente, se han relativizado, siendo escasa su incidencia real sobre el aislamiento social del grupo militar, bien que en conexión con otros su importancia se vea acrecentada; en otros se han producido significativas alteraciones en los últimos tiempos. Nos referiremos someramente a estos factores.

A) En lo que al indice de autorreclutamiento se refiere, cabe destacar que es muy elevado, habiendo superado en determinados períodos el porcentaje del 80 por $100^{40}$, y siendo en la Armada en donde ese índice alcanza sus mayores cotas. Bien es verdad que en los últimos años tiende a disminuir, manteniéndose en todo caso en niveles altos; así lo revela el cuadro 1, que nos ha sido facilitado por el Servicio de Estudios de la Academia General Mi-

${ }^{37}$ Morris Janowitz y Roger W. LitTle, Sociology and the Military Establisbment, 3.² ed., Sage Publications, Beverly Hills-Londres, 1974, p. 96.

38 Julio Busquets, El militar de carrera en España, op. cit., 2." ed., 1971, p. 272.

39 Julio Busquets, El militar de carrera..., ed. de 1984, p. 213.

40 Cfr., al respecto, Julio Busquets, El militar de carrera..., op. cit., Barcelona, 1984, pp. 155 y ss. 


\section{CUADRO 1}

\section{$A G M$}

\begin{tabular}{|c|c|c|c|c|c|c|c|c|c|c|}
\hline Curso & escolar & Promoción & Instancias & $\begin{array}{l}\text { Hijos } \\
\text { militar }\end{array}$ & $\begin{array}{c}\text { Hijos } \\
\text { civil }\end{array}$ & Ingresados & $\begin{array}{c}\text { Hijos } \\
\text { militar } \\
\text { ingresados }\end{array}$ & $\begin{array}{c}\text { Hijos } \\
\text { civil } \\
\text { ingresados }\end{array}$ & $\begin{array}{l}\text { Hijos } \\
\text { militar } \\
(\%)\end{array}$ & $\begin{array}{l}\text { Hijos } \\
\text { civil } \\
(\%)\end{array}$ \\
\hline $1979-80$ & $\ldots \ldots \ldots$ & XXXIX & 2.951 & 1.457 & 1.494 & 329 & 205 & 124 & 62,31 & 37,69 \\
\hline $1980-81$ &.$\quad \ldots \quad \ldots$. & $\mathrm{XL}$ & 3.071 & 1.429 & 1.641 & 297 & 173 & 124 & 58,24 & 41,76 \\
\hline $1981-82$ & $. \quad \ldots, \ldots \ldots$ & XLI & 3.539 & 1.439 & 2.050 & 289 & 153 & 136 & 52,94 & 47,06 \\
\hline $1982-83$ & $\begin{array}{lll} & \ldots & \ldots\end{array}$ & XLII & 4.067 & 1.676 & 2.391 & 312 & 169 & 143 & 54,16 & 45,84 \\
\hline $1983-84$ & . $\ldots \ldots \ldots$ & XLIII & 3.691 & 1.675 & 2.016 & 232 & 129 & 103 & 55,60 & 44,40 \\
\hline $1984-85$ &.$\ldots \ldots \ldots$ & XLIV & 3.908 & 1.795 & 2.113 & 234 & 158 & 76 & 67,52 & 32,48 \\
\hline
\end{tabular}

\section{AGBS}

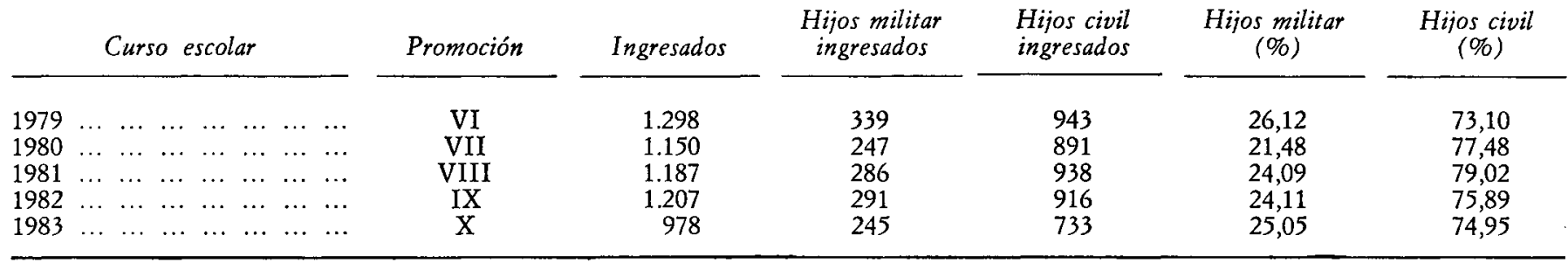


litar, con datos elaborados desde el curso $1979-80$ y que abarcan tanto la AGM como la Academia General Básica de Suboficiales.

Por lo que a la $A G M$ se refiere, es de destacar el importante crecimiento en los aspirantes hijos de civiles y el aumento del porcentaje de éstos entre los ingresados, que quiebra de modo un tanto espectacular en el curso 1984-85. En lo que afecta a la AGBS, resalta de ese cuadro el mantenimiento más o menos uniforme $-\mathrm{y}$ en valores sensiblemente reducidos- del índice de autorreclutamiento.

Una visión de conjunto muy completa, pues abarca el período 1955-1985, nos la ha suministrado Morales Villanueva ${ }^{41}$, bien que ciñéndose de modo específico a los oficiales de Academia de la Guardia Civil. En ese período de tiempo, nada menos que un 78,92 por 100 del total de oficiales procedían de familias del que el autor llama "grupo militar», frente a un 21,08 por 100 procedente del «grupo civil»; a su vez, destaca el hecho de que del porcentaje inicial, un 60,75 por 100 procedía específicamente de familias de la Guardia Civil. Como puede constatarse con facilidad, es altísimo el índice de autorreclutamiento, y más aún si se tiene en cuenta que estamos en presencia de un índice promedio a lo largo de seis lustros.

Del análisis de los datos relativos al origen social de los oficiales, Busquets deduce una importante conclusión por lo que al tema del aislamiento se refiere $^{42}$ : en los tres Ejércitos - advierte el citado autor- existe un fuerte espíritu de cuerpo, o corporativismo, que les hace preferir a los aspirantes pertenecientes a familias militares.

En todo caso, debemos constatar que, pese a detectarse en los últimos años un retroceso del índice de autorreclutamiento, es lo cierto que éste sigue presentando niveles verdaderamente elevados que, desde luego, inciden de modo significativo en el aislamiento social del grupo social castrense.

B) Por lo que se refiere a la autosuficiencia del grupo social militar, cabe significar que resulta propiciada por circunstancias muy dispares, entre las que cabe recordar las prestaciones sociales que, de modo particularizado, reciben los militares, y que son fruto en buen grado de la precariedad económica en que han vivido y - -en menor medida - aún hoy viven. Es el caso de las prestaciones sanitarias, de ocio (clubes y casinos militares...), de vivienda (existen auténticos barrios militares en algunas de nuestras ciudades), educativas (existencia de colegios para hijos de militares), etc.; si a todo ello añadimos el alto índice de endogamia social y la circunstancia de que, por su propia naturaleza, el trabajo militar no se encuentra en contacto directo con el resto de la población, comprenderemos por qué siguen existiendo causas, que bien podríamos considerar «exógenas», que perpetúan el aislamiento o, por lo me-

${ }^{41}$ Antonio Morales Villanueva, El ingreso, la formación y el perfeccionamiento del oficial de Academia de la Guardia Civil, ponencia presentada al II Congreso de Sociología, Santander, 1984, p. 26.

${ }_{42}$ Julio Busquers, El militar de carrera..., op. cit., ed. de 1984, p. 159. 
nos, que dificultan la necesaria integración. Y ello en el bien entendido de que, a nuestro modo de ver, la trascendencia de las circunstancias citadas radica, más que en cada una de ellas aisladamente considerada, en el efecto multiplicador que produce su conjunción, pues si analizamos algunas de las circunstancias anteriores, individualizadamente, veremos cómo su incidencia es muy relativa; es obvio, por ejemplo, que no sólo los militares desarrollan su trabajo al margen del público y, sin embargo, de otras profesiones en las que se produce tal evento no se sostiene que el mismo genere su aislamiento social; por otro lado, si nos ceñimos al factor relativo a las viviendas militares, no cabe por menos de constatar que los miembros de la profesión armada que habitan viviendas de esa naturaleza son tan sólo un porcentaje reducido, y que también en otras profesiones (en especial en el campo del funcionariado) existen viviendas del mismo tipo.

C) En cuanto a la vida intelectual, no creemos que hoy pueda seguir siendo considerado este factor como potenciador del aislamiento social del grupo militar. Basta con atender a los estudios universitarios, cursos de especialización realizados, diplomas obtenidos y, más recientemente, participaciones en congresos, publicaciones, etc., que vienen realizando los militares, para llegar a la conclusión de que niveles significativos de oficiales mantienen una vida intelectual que es perfectamente equiparable a la de otros sectores profesionales de nivel universitario y de naturaleza civil ${ }^{43}$. Nos bastará, a modo de constatación empírica, con traer a colación los datos proporcionados por Morales Villanueva ${ }^{44}$ con relación a las veinte primeras promociones de oficiales de Academia de la Guardia Civil, datos de los que se deduce, en una consideración conjunta de las veinte promociones, que el 35 por 100 de sus componentes poseen una carrera universitaria (véase cuadro 2). Signifiquemos, por último, como hecho trascendente en cuanto se refiere a la «apertura social» de los Ejércitos en España, la periódica celebración de Jornadas científicas entre distintas Universidades españolas y el Centro Superior de Estudios de la Defensa Nacional, con participación conjunta de civiles y militares.

En definitiva, es evidente que hoy siguen subsistiendo causas que potencian el aislamiento social de la institución militar; sin embargo, cada vez en mayor grado, se pueden apreciar distintas circunstancias que atenúan ese aislamiento y que se dirigen hacia la integración. Es claro, desde luego, que sigue existiendo una cierta incomprensión por ambas partes, en los mismos términos posiblemente a que ya aludiera Janowitz ${ }^{45}$; sin embargo, hoy, los problemas de entendimiento entre sociedad y comunidad militar presentan,

${ }^{43}$ Cfr., al respecto, Julio Busquets, El militar de carrera en España, op. cit., ed. de 1984 , pp. 234 y ss.

* Antonio Morales Villanueva, El ingreso, la formación y el perfeccionamiento del oficial de Academia de la Guardia Civil, op. cit.; cfr., en especial, pp. 10-15, acerca del «nuevo oficial».

${ }_{45}$ Morris Janowitz, The Professional Soldier, op. cit., p. 3. 


\section{CUADRO 2}

\begin{tabular}{|c|c|c|c|}
\hline Promoción & Componentes & $\begin{array}{c}\text { Títulos } \\
\text { universitarios }\end{array}$ & $\begin{array}{c}\text { Título/persona } \\
\text { (\%) }\end{array}$ \\
\hline 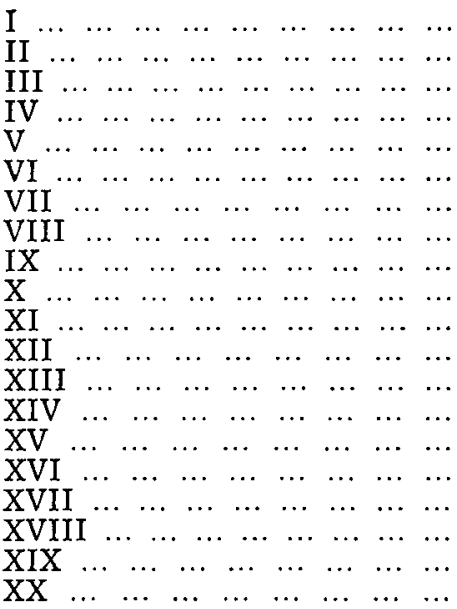 & $\begin{array}{l}29 \\
25 \\
26 \\
24 \\
23 \\
27 \\
33 \\
46 \\
29 \\
31 \\
32 \\
26 \\
33 \\
32 \\
27 \\
31 \\
29 \\
30 \\
30 \\
32\end{array}$ & $\begin{array}{r}11 \\
16 \\
12 \\
8 \\
10 \\
11 \\
12 \\
14 \\
15 \\
22 \\
13 \\
7 \\
9 \\
9 \\
10 \\
8 \\
9 \\
8 \\
6 \\
4\end{array}$ & $\begin{array}{l}37 \\
64 \\
46 \\
33 \\
43 \\
40 \\
36 \\
30 \\
51 \\
70 \\
40 \\
26 \\
27 \\
28 \\
37 \\
25 \\
31 \\
26 \\
20 \\
12\end{array}$ \\
\hline & 594 & 211 & 35 \\
\hline
\end{tabular}

Fuente: Antonio Morales Villanueva, El ingreso, la formación..., op. cit., p. 13. Elaboración a partir de los datos obtenidos del Servicio de Informática y de la escalilla de 1982.

como destaca López de Sepúlveda ${ }^{46}$, matices sustancialmente diferentes. La vieja dicotomía entre militarismo versus antimilitarismo está, si no superada, sí al menos muy amortiguada. Es cierto que subsisten grupos sociales más o menos aislados que, bajo ropajes variopintos, sustentan posicionamientos antimilitaristas, como también lo es la existencia de trasnochados militaristas, verdaderos instigadores de la rebelión militar ${ }^{47}$; sin embargo, parece incuestionable que las posturas maximalistas y las antiposturas se hallan en clara regre-

46 Francisco LóPEz dE Sepúlveda, «Sociedad y Fuerzas Armadas» (I), en Ejército, núm. 504, enero 1982, pp. 13 y ss.; en concreto, pp. 15-16.

47 Estas posturas extremadas preocupan a los miembros de la institución militar, algunos de cuyos medios de difusión han prestado atención específica a las mismas. Buena prueba de ello nos la aporta la revista de pensamiento militar Reconquista. En el editorial del núm. 342 (septiembre 1978), p. 3, se trataba del tema del «Militarismo trasnochado». Un nuevo editorial, esta vez en el núm. 375 (septiembre 1981), p. 5 , se dedicaría al «Antimilitarismo». Reflejaremos algunos párrafos de este último: «Tratar de acallar la voz neutral de los Ejércitos - se puede leer-, instigar a la desunión entre sus miembros y envenenar a la opinión pública para que recele de los profesionales de las armas son objetivos clásicos que muchas veces, bajo la máscara de beatífico pacifismo, lo que realmente persiguen es la quiebra de la Institución que es soporte indispensable del Estado.» 
sión en nuestras sociedades. Y, asimismo, el otrora arraigado pensamiento que establecía una relación de causa a efecto entre militares y guerra es obvio que hoy no se mantiene en pie. Las guerras no existen porque haya profesionales de la Milicia, sino que éstos, como se ha señalado ${ }^{48}$, tienen razón de permanencia porque la Humanidad, en su progreso creciente y constante, todavía no ha conseguido erradicar el fenómeno guerra. De ahí la trascendencia de restituir al militar la conciencia de ser un instrumento de paz, que no de guerra, lo que, a su vez, exige que cumpla su misión en perfecta armonía e integración con el resto de la sociedad en la que se imbrica. Y ello, asimismo, entraña que la aportación de los miembros de los Ejércitos sea consciente y razonable, no mecánica y heroica, alejándose así la venalidad guerrera y el estímulo de la hostilidad.

Cuanto acabamos de señalar nos muestra la ineludible necesidad de que el aislamiento ceda el paso a la integración, circunstancia que se hace aún más perentoria si atendemos a las transformaciones sociales y al influjo diverso que las mismas han producido sobre los Ejércitos, que en nuestros días se ven enfrentados a retos muy diversos ${ }^{49}$; así, por ejemplo:

a) A un nuevo tipo de guerra, la revolucionaria o ideológica, que propicia la aparición de nuevos tipos de Ejércitos y la ruptura de las «leyes de la guerra».

b) Al impacto de la moderna tecnología, que ha venido a revolucionar los planteamientos tácticos y estratégicos tradicionales.

c) A una crisis de identidad por mor de la puesta en cuestión de algunos de los otrora inamovibles valores de la institución militar.

d) A las nuevas implicaciones que para los Ejércitos ha entrañado el concepto polemológico de la «disuasión».

En resumen, pues, hoy la institución militar se ve afectada por múltiples factores que inciden, asimismo, sobre el conjunto de la sociedad, provocando el cambio social; el influjo de esos factores, a la par que transforma al instituto armado, provoca su acercamiento a la sociedad civil: «the civilianizing of the military profession», como dijera Janowitz ${ }^{50}$; en definitiva, la integración social de la clase militar.

Ese complejo de variables a que venimos refiriéndonos afecta no ya a las que podríamos tildar de «causas exógenas» del aislamiento militar —a las que aludiéramos con anterioridad-, sino a las causas más profundas que tradicionalmente han venido sustentando ese aislamiento: el carácter vocacional de la milicia; la peculiar configuración de la enseñanza militar como canal trans-

${ }^{48}$ Francisco López de Sepúlveda, «Sociedad y Fuerzas Armadas» (I), op. cit., p. 18.

${ }^{49}$ Cfr., al respecto, José M. ${ }^{a}$ Riaza Ballesteros, Líneas generales de la reforma de la enseñanza militar, ponencia presentada al II Congreso de Sociología, Santander, 1984, pp. $6-7$.

50 Morris Janowitz, The Professional Soldier, op. cit., pp. 31-32. 
misor de la particular escala valoral de la institución; el carácter corporativo de los Ejércitos; su peculiar «ideología»; su misma fisonomía estructural, y aun su finalidad especialmente trascendente para el Estado y, por tanto, para la sociedad en que el mismo se asienta. Estos elementos -en los que el aislamiento social de la institución ha encontrado buen sustento- se han visto afectados por aquel elenco de variables a que antes nos refiriéramos, transmutándose, en algunos casos, de elementos propiciadores del aislamiento a factores generadores de integración. Vamos, pues, a renglón seguido, a referirnos a cada uno de ellos.

\section{La Milicia: ¿vocación o profesión?}

Alrededor de la Milicia se mantiene todavía toda una argumentación que viene a justificar el sentido vocacional de la misma, rasgo que, como se subraya ${ }^{51}$, es característico de un conjunto de actividades gremiales de carácter preindustrial, que apenas han evolucionado, con lo cual este rasgo, de un modo u otro, vendría a incidir en el relativo aislamiento de la institución castrense.

\section{¿Qué significado tendría este carácter vocacional?}

Paricio lo entiende en el sentido de que a la dimensión material apenas se le otorga el más mínimo sentido si no se encuentra acompañada de un contenido trascendental y definido en una serie de virtudes que son celosamente guardadas y transmitidas por los centros de formación militar ${ }^{52}$. Es más, se ha llegado a advertir que la definición del Ejército como profesión se opone a la definición y al arraigo social del contenido de la institución militar, término éste de orden espiritual que sobrevive a sus miembros y les insta a que interioricen una pauta prescrita de comportamiento que ellos no han dibujado y sobre la que están sólo autorizados a la renovación ${ }^{53}$.

En consonancia con este modo de concebir la Milicia, se estima que «adscribirse» a la profesión militar lo que en verdad significa es «profesar», entendido este término no en el sentido en que lo hace Hughes ${ }^{54}$ cuando significa que los profesionales «profesan», esto es, conocen mejor que otros la naturaleza de ciertas materias y mejor que sus clientes los problemas que les preocupan -ésta es la esencia de la idea de profesión y de la pretensión de profesionalidad ${ }^{55}$-, sino en el sentido de «aceptar una fe y prometer una en-

51 Jesús Martínez Paricio, Para conocer a nuestros militares, op. cit., p. 43.

52 Ibidem, p. 146.

${ }^{53}$ Miguel Alonso Baquer, «Objeto de la Sociología de las Fuerzas Armadas o Sociología Militar», en el colectivo Primeras Jornadas FAS-Universidad, Centro Superior de Estudios de la Defensa Nacional, Madrid, 1982, pp. 101 y ss.; en concreto, p. 105.

${ }_{54}$ Everett C. Hug Hes, «Professions», en K. S. LynN (comp.), The Professions in America, Beacon Press, Boston, 1967, p. 2.

${ }_{55}$ Cit. por Bengt ABRA HAMSSON, «La socialización profesional: teoría, ética y espíritu de cuerpo", en Rafael Bañón y José A. Olmeda (comps.), La institución militar en el Estado contemporáneo, op. cit., pp. 208 y ss.; en concreto, p. 210. 
trega perfecta y apasionada de todo lo mejor que hay en los miembros de la Milicia al servicio de esos valores sagrados que no deben' perecer - que forman en su conjunto la Patria-, y no para vivir de ellos, sino para que ellos subsistan» ${ }^{56}$.

El militar, se afirma por otro lado ${ }^{57}$, posee una vocación por la carrera de las armas. Tal vocación hace que el uniforme, la disciplina, el sentido del honor y de misión, el de sacerdocio también, transformen a una persona hasta el punto de comportarse de otra manera, y siempre con abnegado espíritu de servicio.

$Y$, en lógica sintonía con tales ideas, se considera a la Milicia como una especie de sacerdocio, pensamiento que encontramos en cierto número de nuestros escritores militares. Así, Vigón proclamará ${ }^{58}$ : «nuestra profesión es un sacerdocio, $\mathrm{y}$, como tal, exige cierto número de virtudes, cuya carencia debiera excluir a quien la sufriera del ejercicio del mando». Y en la revista de pensamiento militar Reconquista hallamos numerosas manifestaciones de este modo de pensar ${ }^{59}$.

${ }^{56}$ Emilio Romero Salgado, Temas de Moral Militar, op. cit., p. 24.

57 Luis SÁEZ DE GovanTes, «El Ejército y la Política», en Reconquista, núm. 343, octubre 1978, pp. 50-51.

s8 Jorge VIGón, Estampa de capitanes..., op. cit., p. 24.

s9 Así, Govantes (en «Religión y Milicia», núm. 402, marzo 1984, p. 12) considera a la profesión militar como una especie de sacerdocio, mientras que Pedro DE CóRdOBA (en «Vocación militar y vocación cristiana», en Reconquista, núm. 371, abril 1981, p. 59) estima que las exigencias de la vocación militar y la vocación cristiana son muy semejantes, y el mismo autor (en «Religión, Patria, Milicia», núm. 345, diciembre 1978, p. 58) advierte que religión y Milicia coinciden en que ambas dan primacía al espíritu y conducen al hombre desde los deberes a los derechos, bien que la religión presente una dimensión superior sobrenatural.

En otro momento, y en un editorial de la propia revista (núm. 382, abril 1982, p. 5), se afirma que Dios y las armas nunca fueron conceptos antagónicos y, a modo de argumento con el que refrendar tal afirmación, se acude a la religiosidad del guerrero, que es algo comprobable por cualquier estudioso de la Historia. Casi podría decirse que es consustancial a su naturaleza. Porque el soldado, conocedor del constante riesgo que su vida corre, idealiza la muerte y confía en un más allá donde se premien sus fatigas y se compense su posible sacrificio humano. Y el cadete, se apostilla en otro lugar (Fernando SANZ Esteban, «La profesión militar: ¿vocación o medio de vida?», en Reconquista. núm. 359 , marzo 1980 , pp. 7-8), aspira a ser un guerrero, no un funcionario.

De ahí que se insista en la necesidad de una adecuada preparación espiritual por parte de los miembros de la institución, pues no basta saber manejar armas perfectas. Y ni siquiera la idea de Patria es suficiente, aunque tendría que serlo, pero al haber sido dicha idea carcomida por las ideologías ya no inspira la misma devoción que antes, por lo que, según Vintila Horia ( «La formación espiritual en el marco de la tercera guerra mundial», en Reconquista, núm. 378, diciembre 1981 , pp. 9-10), esa idea de Patria tiene que fundarse en la religión. «Una Patria no espiritual — manifiesta el citado autor- no es más que pura geopolítica, y creo que nadie es capaz de sacrificar su vida en el nombre de una disciplina o de unos conceptos más o menos coincidentes con la realidad.»

En conexión precisamente con esa necesidad, se subraya (Vicente Alejandro PÉREz, «Soporte espiritual», en el núm. 378, diciembre 1981, p. 13): «Sólo un concepto de Patria, única e indivisible, con los valores que incluye y que abarcan toda la gama de contenido positivo en virtudes del alma, es capaz de dar cimiento sólido y proyección de futuro a la actuación del guerrero: No es la paga ("las algarrobas de los bueyes y por las cuales son felices"), sino la satisfacción del deber cumplido, la paz interior surgida de la confluencia 
En conexión con esa óptica particular creemos que debe situarse la primacía que se quiere otorgar al factor religioso en el ámbito castrense. En cuanto constituyente de una dimensión radicalmente humana, ese factor aparece como un valor que tiene mucho que ver con las virtudes castrenses del deber, la solidaridad y el compañerismo. De ahí, se afirma ${ }^{60}$, que la institución militar no pueda ignorar en su conjunto la situación religiosa de los hombres que incorpora a sus filas.

Este supuesto peso específico de lo religioso dentro del mundo de la $\mathrm{Mi}$ licia no sólo contribuye a forjar el carácter vocacional de la misma, sino que se estima previsible que coadyuva a otorgar a sus miembros unos rasgos diferenciadores - al menos en lo que a sus sentimientos y modo de pensar se refiere- respecto a otros grupos sociales; esta consideración, que, como resulta obvio, no puede ser estimada sino como mera hipótesis de trabajo, se ha llegado a estimar empíricamente ratificada ${ }^{61}$.

Pero no es sólo esta afinidad con lo religioso lo que confiere un significado vocacional a la profesión castrense, sino que tal carácter deriva, asimismo, de la íntima conexión de tal profesión con otros valores espirituales. Con referencia a nuestros Ejércitos de principios de siglo, Cardona, no sin razón, advierte ${ }^{62}$ que, al margen del reducido grupo de militares africanistas, los oficiales se encontraban vinculados a una profesión que no existía, pues la mayoría carecía de tropa que mandar. De ahí que ser militar fuera, en realidad, un conjunto de actitudes morales y un código de costumbres, pero no el ejercicio de una actividad.

En todo caso, es lo cierto que, ya desde una visión un tanto intemporal, sacrificio, deber, abnegación, austeridad, oblación, etc., constituyen otros tantos valores de naturaleza espiritual que animan e impulsan a «profesar» en la Milicia. Más aún, el exacto cumplimiento del deber, inspirado - como prescribe el artículo $1 .^{\circ}$ de las Reales Ordenanzas-- por el amor a la Patria, el honor, la disciplina y el valor, es el norte verdadero al que deben dirigir su actuación todos los miembros de la institución armada. Y ese deber, diría Vigón ${ }^{63}$, es un vínculo de naturaleza moral; no es cosa de ciencia, sino de convicciones;

entre lo sentido y lo realizado, el paralelismo de estar y ser, lo que da fuerza moral y coraje a un ejército en la acción.»

"Vicente José SASTRE García, «El factor religioso en la juventud castrense», en Reconquista, núm. 389, diciembre 1982, pp. 6-10; en concreto, p. 6.

${ }_{61}$ En unas declaraciones efectuadas por monseñor Benavent, vicario general castrense, a la revista Reconquista (núm. 343, octubre 1978, pp. 14-17; en concreto, p. 16) se afirmaba por el entrevistado que los militares «son hombres de una religiosidad muy superior a la media, entendiendo por esa religiosidad la adhesión a la vida religiosa practicante, y que aunque es posible que los más jóvenes se hallen afectados por la crisis religiosa de la juventud actual, pues, al fin y al cabo, son hombres de su tiempo, es lo cierto que en las Academias Militares se obtiene un índice de religiosidad más elevado que el de los grupos universitarios civiles».

${ }^{62}$ Gabriel Cardona, El poder militar en la España contemporánea..., op. cit., p. 7.

${ }^{63}$ Jorge VIGón, El espíritu militar español, Ediciones Rialp, Madrid, 1950, p. 112. 
implica, primero, una afirmación, un acto de fe, y, en último término, un riesgo, una intimidación.

En definitiva, pues, la vida militar, según advierte Gárate Córdoba ${ }^{64}$, como toda profesión en la que se profesa vocacionalmente, mira más y antes a las obligaciones que a los derechos. Por ello, y precisamente en relación con las Reales Ordenanzas, el propio autor justifica que las mismas resulten ser más un conjunto de reglas éticas, de conduçta, esto es, una norma moral, mejor que jurídica, donde lo que se exige como obligación se impone en la conciencia del militar como deber, que es más.

Ahora bien, las transformaciones sociales, de un lado, y tecnológicas, de otro, han venido a afectar a la institución armada tan profundamente que algún autor incluso ha llegado a hablar de una auténtica "revolución militar» ${ }^{65}$ experimentada por los Ejércitos en su seno y por la que han quedado sin sentido muchas de las antiguas concepciones ${ }^{66}$. Tan visible es esa revolución que Janowitz ${ }^{67}$ ha llegado a describir la historia reciente del instituto armado como la resultante de la pugna entre los beroic leaders, que personifican la tradición y el heroísmo del soldado de antaño, y los military managers, preocupados por la conducción científica y racional de la guerra.

Como al efecto señala Oehling ${ }^{68}$, hoy parece claro que los militares se han lanzado por el camino de la técnica. La especialización se ha hecho más necesaria en los Ejércitos; esta circunstancia ha desarticulado la antigua postura cerrada e introvertida del militar. El sentimiento de casta, el ethos militar y la adoración de las virtudes guerreras han tenido que transformarse, al extremo de convertir al militar en un ciudadano de uniforme, con lo que mientras el beroic leader de que hablaba Janowitz aparecía como una perpetuación del guerrero arquetípico, personificando el espíritu marcial y el valor personal, el military manager refleja las dimensiones científica y pragmática del desarrollo de la guerra, y aún, junto a él, Janowitz coloca ${ }^{69}$ al military technologist, esto es, al militar interesado por la incorporación del desarrollo científico y tecnológico de la sociedad civil a la militar.

Bien es verdad que no han faltado quienes se han opuesto a admitir tales cambios en base a la existencia de unos «fundamental, immutable, eternal, unchanging and unchangeable principles of war»; desde luego, como significa

64 José M." Gárate Córdoba, «Del deber, de la Patria y del honor», en Reconquista, núm. 351, junio 1979 , p. 48.

${ }^{65} \mathrm{Cfr}$, al respecto, Fritz Sternberg, La revolución militar e industrial de nuestro tiempo, FCE, México, 1961.

${ }^{6}$ Según Hermann Oe hilng (en Valoración social de la ética militar, trabajo inédito, p. 10), existen axiomas militares que hoy parecen no darse en el hombre militar, especialmente comparando las épocas más recientes y próximas.

${ }^{67}$ Morris Janowitz, The Professional Soldier, op. cit., p. 21.

${ }^{68}$ Hermann Oe h ling, La función politica del Ejército, Instituto de Estudios Políticos. Madrid, 1967, p. 173.

${ }^{69}$ Morris Janowitz, The Military in the political development of new nations. An essay in comparative analysis, The University of Chicago Press, Chicago, 1964, p. 41. 
Huntington ${ }^{70}$, los historiadores militares difieren acerca del número y contenido de estos principios, pero no cuestionan su existencia y su naturaleza de «the fundamental core of military science». Ahora bien, como el propio autor advierte, la aplicación de esos principios, otrora inconmovibles, está sometida hoy en día a un cambio constante por mor de las transformaciones tecnológicas y de la propia organización social. Consecuentemente, no parece que tales principios puedan servir de soporte para la defensa de la perpetuación del beroic leader. Más aún, el propio futuro de la profesión depende de la progresiva adaptación a los cambios tecnológicos y políticos de la sociedad en que se imbrica, bien que tales mutaciones deban en todo caso acomodarse a la estabilidad que la propia estructura organizativa de la institución exige; así lo ha puesto de relieve Morris Janowitz ${ }^{71}$.

Las modificaciones descritas han venido a afectar, aun cuando haya sido de modo tangencial, al carácter vocacional de la Milicia. Bien es verdad que tienen especial trascendencia en relación con la eficacia y competencia de la oficialidad los llamados military ideals ${ }^{72}$, pero no es menos cierto que la profesionalización es el rasgo que con más fidelidad define a la institución castrense en las sociedades de nuestro tiempo; como subraya Santos ${ }^{73}$, la carrera militar exige cada día una mayor profesionalidad. De este modo, el Ejército incorpora al ideal patriótico el prestigio de su propia eficacia, eficacia que está reñida con una orientación convencional y rutinaria de la profesión ${ }^{74}$ y que se presenta conectada con el rol de las FAS en la dirección de la violencia dentro del Estado ${ }^{75}$, sin que ello implique confundir — tal y como hiciera Augusto Comte- el espíritu bélico con la casta militar.

Hoy puede afirmarse que la influencia de la tecnología sobre lo que se dio en llamar la «mentalidad militar» está sujeta a un proceso de continuo crecimiento. Los avances tecnológicos liberan posibilidades humanas que necesariamente operan sobre las convicciones más arraigadas de los integrantes de la Milicia. Consecuencia de todo ello es la apertura de una problemática ética cada vez más dispar. La reconversión táctica que exige el empleo de las nuevas armas, los mortíferos y devastadores efectos de su utilización, e incluso la mayor deshumanización que entraña su empleo, respecto de las armas más convencionales, son otras tantas circunstancias que, al operar una profunda

${ }^{70}$ Samuel P. Huntington, The soldier and the State. The theory and politics of civilmilitary relations, The Belknap Press of Harvard University Press, Cambridge (Massachusetts), 5. impr., 1972, p. 71.

${ }^{71}$ Morris Janowitz, The Professional Soldier..., op. cit., p. 417.

${ }^{22}$ Samuel P. Huntington (en The soldier and the State..., op. cit., p. 74) vincula la eficacia y competencia de la oficialidad en relación directa al grado de motivación de la misma por los military ideals.

${ }^{73}$ Anselmo SANTOS, La educación cívica de los militares, desde los esquemas clásicos a la postmodernidad, ponencia presentada al II Congreso de Sociología, Santander, 1984, p. 24.

${ }^{24}$ Cfr., al efecto, Arthur K. Davis, «Bureaucratic Patterns in the Navy Officer Corps», en Social Forces, núm. 27, 1948, pp. 143 y ss.

${ }_{75}$ Gwyn Harries-Jenkins, «Armed Forces and the Welfare State», op. cit., p. 238. 
transformación de los Ejércitos, suscitan abundantes situaciones de conflicto que, en muchos casos, han venido a replantear la cuestión de la vigencia actual de diversos conceptos éticos fundamentales.

En esta misma dirección, Martín Jiménez ${ }^{76}$ ha llegado a considerar que la influencia de la tecnología sobre ese código peculiar de valores que da vida a la mentalidad militar es superior a la de ninguna otra fuerza. Y Cabeza Calahorra ${ }^{n}$ pone de relieve que el auge de lo tecnológico tiende a configurar la sociedad militar del tipo competitivo, provocando una cierta similitud con el mundo de los negocios, con aceptación del beneficio económico, veneración de la objetividad científica y adopción consiguiente de una neutralidad moral.

Estas civilianizing tendencies, a que se refiriera Janowitz ${ }^{78}$, que afectan a la institución armada, al relativizar la trascendencia de algunas de las virtudes militares más celosamente custodiadas y transmitidas por las Academias Militares, han propiciado que la profesión militar pierda un tanto de su matiz vocacional, en tanto en cuanto la guerra exige unos profesionales impuestos en las técnicas más sofisticadas, lo que, por otro lado, propicia una organización militar que debe ser dirigida y organizada con técnicas cada vez más afines a las que rigen para otro tipo de organizaciones civiles.

Junto a las circunstancias descritas, cabe señalar que en los últimos tiempos se ha producido una pérdida de prestigio (prestigio medido sobre la base del interés hipotético de los jóvenes para acceder a una profesión) en las sociedades occidentales por parte de la institución armada; así lo pone de relieve Janowitz ${ }^{79}$, que, por lo que respecta a Estados Unidos, significa que elegir la carrera militar es allí una pobre elección, dado que hay un mayor énfasis en los valores comerciales y en el éxito de los negocios; se trata de una elección pobre porque se ha optado por una carrera que no representa una ambición fuerte, unos ideales poderosos o un sentimiento de autovaloración personal. Ahora bien, a renglón seguido, el propio Janowitz apunta que, a pesar del bajo prestigio (entendido en el sentido precitado) de la carrera militar, ésta representa una opción importante, al menos para una minoría considerable de jóvenes, y especialmente para aquellos del binterland. Para estos jóvenes, la institución militar representa los valores fundamentales y deseables y la posibilidad de alcanzar una imagen de liderazgo en su aprendizaje profesional. $\mathrm{Y}$ qué duda cabe que en el atractivo que aquellos valores ejercen ha de contar necesariamente ese carácter sui generis de la profesión militar, respecto de la cual Janowitz ${ }^{80}$ cree que «is more than an occupation; it is a complete style

${ }^{76}$ Hilario Martín Jiménez, Los valores morales de las Fuerzas Armadas en las Reales Ordenanzas de S. M. don Juan Carlos I, Litomaype, La Laguna, 1980, p. 37.

77 Manuel Cabeza Cala h orra, «La socialización militar», en Ejército, núm. 516, enero 1983 , pp. 3 y ss.; en concreto, p. 6.

${ }_{78}$ Morris Janowitz, The Professional Soldier..., op. cit., p. 33.

79 Morris JANOWITZ, «La organización interna de la Institución Militar», en Rafael Bañón y José A. Olmeda (comps.), La Institución Militar en el Estado contemporáneo, op. cit., pp. 101 y ss.; en especial, pp. 125-127.

${ }^{80}$ Morris JanowtTz, The Professional Soldier..., op. cit., p. 175. 
of life»; no en vano el oficial es miembro de una comunidad cuyos requerimientos sobre su existencia cotidiana van más allá de sus deberes u ocupaciones oficiales.

Quizá en buena parte por algunas de estas consideraciones, Huntington ${ }^{81}$ haya significado que aunque en la práctica ninguna vocación, ni tan siquiera la medicina ni la abogacía, reúne todas las características del tipo ideal profesional, la oficialidad, probablemente, queda algo más cerca del ideal que algunas de aquéllas.

En resumen, pues, la pérdida relativa de ese carácter vocacional propio de la Milicia en un pasado no lejano va íntimamente unida, a nuestro modo de ver, con el progresivo abandono del heroic leader como perpetuación del guerrero arquetípico, símbolo del espíritu marcial y del valor personal, y su sustitución por el military manager, con todo lo que ello supone de recambio de unos valores por otros. Todo ello ha entrañado que el militar sea considerado como un experto en un área particular de conocimientos ${ }^{82}$. Ahora bien, estas mutaciones no han suprimido, en modo alguno, el llamado «espíritu del combatiente»; Janowitz se refiere ${ }^{83}$ a «the persistence of the fighter spirit», manifestando al respecto que los militares no han perdido - pese a los cambios apuntados- sus características distintivas; las exigencias del combate - termina Janowitz- marcan los límites de las «civilianizing tendencies». Perlmutter, con el ánimo de destacar ese carácter de totalidad que, a diferencia de otras, se dice que ofrece la profesión militar, indica que «the officer's only "life" is his profession»"

Y Teitler ${ }^{85}$ caracteriza la profesión militar por la competencia técnica de sus miembros, por la prestación de sus servicios al Estado y, además, por ese peculiar esprit de corps anclado en la tradición y conectado a un singular código del honor.

Vemos, pues, cómo la profesión militar sigue estando revestida de unos rasgos en verdad particulares, y en ellos se cimenta esa inclinación, esa atracción, esa, en definitiva, vocación que sigue suscitando en amplios sectores de la juventud.

A la vista de todo lo expuesto, parece claro que la interrogación con la que se abre este epígrafe (¿vocación o profesión?) carece de cierto sentido entendida como contraposición dialéctica entre ambos términos. No creemos,

81 Samuel P. Huntington, «Officership as a profession», en Amos Perlmutter y Valerie Plave Bennet (eds.), The political influence of the Military. A comparative reader, Yale University Press, New Haven y Londres, 1980, pp. 37 y ss.; en concreto, p. 40.

${ }_{82} \mathrm{La}$ vocación militar -afirma Huntington (en The soldier and the State, op. cit., p. 64) - es una profesión porque ha acumulado experiencias que componen e integran un cuerpo de conocimientos.

${ }^{83}$ Morris JANowitz, The Professional Soldier..., op. cit., pp. 31 y ss.

${ }^{84}$ Amos Perlmutter, The Military and Politics in modern times, op. cit., p. 25.

${ }^{85}$ Gerke Teitler, «La génesis de los cuerpos de oficiales profesionales. Aspectos teóricos», en Rafael Bañón y José A. Olmeda (comps.), La Institución Militar en..., op. cit., pp. 161 y ss.; en especial, pp. 165-167. 
desde luego, que hoy pueda establecerse un parangón entre la vocación militar y la vocación al sacerdocio; sí pensamos que estamos en presencia de una auténtica vocación, bien que aureolada de unos rasgos, incluso de unos símbolos, que propician una atracción específica hacia ella por parte de algunas personas. De ahí que podamos suscribir las palabras de García Escudero ${ }^{86}$ cuando advierte que vocación militar es inclinación a la profesión de las armas como medio de realización humana, inclinación que conlleva indiscutiblemente una atracción por un modo de vida y por un sistema de valores, así como por un código de conducta; todo ello propicia que bien pueda hablarse, en aras de una mayor claridad conceptual, de una «atracción intuitiva» hacia la profesión militar ${ }^{87}$.

En cuanto hoy puede constatarse esta evolución, puede asimismo significarse que esta circunstancia ha perdido buena parte de su funcionalidad como elemento coadyuvante al aislamiento social de la institución militar.

\section{Las Academias Militares, marco institucional de transmisión de la mentalidad militar}

La enseñanza militar en las Academias viene considerada tradicionalmente como uno de los factores que en mayor grado incide sobre el aislamiento social de la institución armada.

Abrahamsson ${ }^{88}$ manifiesta al respecto que la profesión militar ha tendido a mantener sus instituciones educativas aisladas de la sociedad civil y a reducir la relación entre los cadetes y la población civil, lo que acelera la asimilación de los valores militares y provee una base funcional para el proceso de «mortificación del yo» y la implantación del nuevo papel; desde esta óptica, no puede extrañar que las Academias Militares hayan sido consideradas por la doctrina ${ }^{89}$ como uno de los mejores ejemplos en los que se cumplen los requisitos señalados por Goffman para las instituciones totales ${ }^{90}$.

Desde luego, el fenómeno de las Academias como centros que propician en cierto grado el aislamiento social de la institución castrense no es nuevo, y, así, Cardona ${ }^{91}$ nos recuerda cómo en la España de la Restauración las Academias Militares desarrollaron una mentalidad basada en la educación espartana, sentido elitista de la condición de oficial e ideales de alta tensión espi-

${ }^{86}$ José M. ${ }^{2}$ García Escudero, "Profesión militar y vocación cristiana», en Reconquista, núm. 391, febrero 1983, p. 40.

${ }^{87}$ Jesús Martínez Paricio, Para conocer a nuestros militares, op. cit., p. 45.

8 Bengt ABRA Hamsson, "La socialización profesional: teoría, ética y espíritu de cuerpo», en Rafael BAÑón y José A. Olmeda (comps.), La Institución Militar en..., op. cit., pp. 208 y ss.; en concreto, p. 212.

${ }^{89}$ Jesús Martínez Paricio, Para conocer..., op. cit., p. 76.

${ }^{90}$ Cfr., al respecto, Erving Goffman, «The Characteristics of Total Institutions», en Amitai Etzioni (comp.), Complex Organizations. A Sociological Reader, Nueva York, 1964, p. 318. Cit. por Bengt ABRA HAMSSON, op. cit., p. 212.

${ }_{91}$ Gabriel Cardona, El poder militar..., op. cit., p. 23. 
ritual, basados en las glorias del Siglo de Oro, actualizadas a base de convicciones nacionalistas.

La circunstancia descrita no es en modo alguno patrimonio exclusivo de nuestro país, pues el propio autor nos recuerda, asimismo ${ }^{92}$, cómo en todos los Ejércitos del siglo XIX y principios del xx las Academias Militares se encargaban de transmitir a sus alumnos el esquema de las ideas dominantes en la institución.

Hoy, el impacto que supone sobre el aspirante a oficial su paso por la Academia está fuera de toda duda. «Education at a service academy —dirá Morris Janowitz ${ }^{93}$ - is the first and most crucial experience of a professional soldier.»

Cabe intuir que el ingreso en un centro en el que se exige un escrupuloso y exacto cumplimiento de las normas reglamentarias, muy rígidas por lo demás; en el que la disciplina, entendida en buena medida como la concibiera Ellis ${ }^{94}$, esto es, como rígida adhesión a unas reglas y subordinación y acatamiento a la autoridad establecida, adquiere posiblemente sus tonalidades más acentuadas; un centro donde el cadete debe adoptar como norte un modelo de vida que, por lo que a España se refiere, aparece recogido en el conocido «Decálogo del Cadete» ${ }^{95}$, y en el que la enseñanza —calificada por Busquets ${ }^{\%}$, en relación a nuestras Academias Militares, de memorística y acrítica-, como significara Janowitz ${ }^{97}$, bien es verdad que refiriéndose de modo específico a la educación sociopolítica de los futuros oficiales, se inspira más en el adoc-

92 Ibidem, p. 22.

${ }_{93}$ Morris Janowitz, The Professional Soldier..., op. cit., p. 127.

${ }^{94}$ Capitán Eugene A. Ellis, «Discipline: Its importance to an Armed Force and the best means of promoting or maintaining it in the United States Army», en Journal of Military Service Institution, 1895, 16, pp. 211-250.

${ }^{95} \mathrm{El}$ «Decálogo del Cadete» reza como sigue:

I. Tener un gran amor a la Patria y fidelidad al Rey, exteriorizado en todos los actos de su vida.

II. Tener un gran espíritu militar, reflejado en su vocación y disciplina.

III. Unir a su acrisolada caballerosidad constante celo por su reputación.

IV. Ser fiel cumplidor de sus deberes y exacto en el servicio.

V. No murmurar jamás ni tolerarlo.

VI. Ser voluntario para todo sacrificio, solicitando y deseando siempre ser empleado en las ocasiones de mayor riesgo y fatiga.

VII. Hacerse querer de sus inferiores y desear de sus superiores.

VIII. Sentir un noble compañerismo, sacrificándose por el camarada y alegrándose de sus éxitos, premios y progresos.

IX. Tener amor a la responsabilidad y decisión para resolver.

$\mathrm{X}$. Ser valeroso y abnegado.

Recordaremos, finalmente, que este «Decálogo», que, según Pedro García Zaragoza - del que lo recogemos- (en «Lo que significa ser hombre en el Ejército», en Reconquista, núm. 352, julio 1979 , p. 52), es un compendio de la más pura esencia de las viejas Ordenanzas Militares, es obra del general Franco, cuando era director de la Academia General Militar de Zaragoza.

96 Julio BusqueTs, El militar de carrera..., op. cit., pp. 256-258.

${ }_{97}$ Morris JANOWITZ y Stephen D. WESBROOK, The political education of soldiers, Sage Publications, Beverly Hills-Londres, 1983, p. 10. 
trinamiento que en la educación cívica; un centro educativo en el que el educando se ve sujeto a tal conjunto de circunstancias, no puede por menos de impactarle fuertemente. De ahí que el propio Janowitz ${ }^{98}$ venga a manifestar que las experiencias educacionales de los cadetes no pueden borrar su origen social, pero dejan, sin embargo, hondas y duraderas impresiones.

Por otra parte, las Academias, más allá de los conocimientos técnicos que adquiere el futuro oficial, deben preparar a los oficiales del mañana para ese particular estilo de vida de la existencia militar. De ahí que el propio Janowitz ${ }^{99}$ haya estimado que «the academies set the standards of behavior for the whole military profession. They are the source of the pervasive likemindedness about military honor and for the sense of fraternity which prevails among military men». $Y$ es que, como en otro momento habrá de manifestar el autor precitado ${ }^{100}$, la común identificación forjada en cuatro (o cinco, añadiríamos nosotros) años produce una fuerte like-mindedness, esto es, una arraigada mentalidad común y una cerrada red de contactos personales, todo lo cual, pensamos por nuestra parte, contribuirá a perfilar a la comunidad militar como una comunidad total y, en cierto modo, autosuficiente.

Ya es sintomático, a estos efectos, que se puedan constatar —en buena parte, creemos, como resultante de buen número de las circunstancias aludidas precedentemente - significativas disonancias en lo que afecta a las opiniones de los cadetes y de los estudiantes universitarios ${ }^{101}$. A este respecto, Díez Nicolás ${ }^{102}$ se ha referido a cómo diversos estudios han puesto de relieve la existencia de ciertas incomprensiones, desconfianzas o reticencias de los universitarios hacia los militares en general. El hecho, que no sólo es exclusivo de nuestro país, tiene que ver con los dos modos o estilos de pensamiento característicos de una y otra actividad profesional; el universitario tiende al discurso, a la duda metódica, a las matizaciones; el militar, por el contrario, y por exigencias de su actividad, da mayor prioridad a la disciplina, a la jerarquía. Es bien conocida a este respecto la expresión castrense de que orden más contraorden igual a desorden. Por contra, en la actividad intelectual, la duda, la contradicción, suelen ser moneda corriente.

En último término, creemos que las diferencias que separan las opiniones de los futuros oficiales y de los estudiantes universitarios se conectan estrechamente con los distintos métodos de enseñanza que rigen en unos y otros centros educativos. Estas divergencias didácticas se han tratado de justificar en nuestro ámbito castrense. Y, así, en una alusión específica a la diferencia

${ }_{98}$ Morris Janowitz, The Professional Soldier..., op. cit., p. 127.

99 Ibidem, p. 127.

100 Ibidem, p. 136.

${ }^{101}$ Cfr., a este respecto, Jesús Martínez Paricio, Para conocer a nuestros militares, op. cit., pp. 127 y ss.

102 Juan DíEz NICOLÁs, «Inquietudes del universitario en relación con la Defensa Nacional», en el colectivo Segundas Jornadas Fuerzas Armadas-Universidad, Centro Superior de Estudios de la Defensa Nacional-Universidad Complutense, Madrid, 1983, pp. 117 y ss.; en concreto, p. 124. 
del acento formativo entre la Universidad y el Ejército, se manifiesta ${ }^{103}$ que mientras en aquélla se busca primariamente la formación de la inteligencia, en el Ejército es la formación de la voluntad. «De aquí —-se añade- la frecuente incomprensión entre intelectuales y militares al aplicar al otro un análisis inadecuado. Los mil detalles de la vida militar se hacen insoportables para los que no alcanzan nada más que lo exterior y tratan o pretenden aplicar a nuestra formación lo que invalidaría el espíritu necesario para afrontar riesgos y fatigas.»

En las Academias —se puede leer en otro momento ${ }^{104}$ - enseñan e inculcan una moral especial; quizá esté basada en la historia grande, en los hechos gloriosos, en los ejemplos de heroísmo, en las virtudes que el uniforme exige. «Desde que ingresamos en la Academia — significa Vázquez Labourdette ${ }^{105}$ - se nos ha repetido muchas veces una frase que de joven nos pareció lapidaria: "La milicia es una religión de hombres honrados".»

Desde luego, es lugar común entre buen número de escritores militares la ineludibilidad de que las Academias suministren una formación moral adecuada, que se verá explicitada en un código ético y moral que se entiende consustancial con la profesión militar ${ }^{106}$. Desde luego, nos parece algo evidente que, por su trascendencia última, los Ejércitos requieren no sólo una eficaz organización material para la contingencia bélica, sino, asimismo, unos recursos espirituales y morales, referidos tanto a su aspecto ético cuanto a su disposición personal y permanente. No sólo en lo que hace referencia a la disposición social para la defensa, que integrada en los Ejércitos se llama «moral militar», sino en cuanto a la decisiva fundamentación en el ánimo individual para una conducta en la que el riesgo de la propia vida es tan visible.

De otro lado, las peculiaridades del sistema militar educativo se han justificado en la necesidad de "prolongar en uno mismo un género de vida valioso recibido por tradición» ${ }^{107}$. En la vida militar, advierte Alonso Baquer, se penetra con el ánimo dispuesto a la asimilación de un legado histórico. La necesaria y conveniente actitud crítica en aras de la modernización de las instituciones militares viene algo después. En una primera mirada - continúa Alonso Baquer- podríamos pensar que el dato incontestable de la interior satisfacción de los alumnos de las Academias y Escuelas Militares está edifi-

${ }^{103}$ Pedro DE CóRdoba, «El Ejército es diferente», en Reconquista, núm. 354, octubre 1979 , p. 59.

to4 Govantes, «Morir por algo», en Reconquista, núm. 374, julio-agosto 1981, p. 13.

10s Manuel VÁzquez LabourdetTe, «La moral del escritor militar», en Ejército (Revista de las Armas y Servicios), núm. 545, junio 1985, pp. 26 y ss.; en concreto, p. 26.

106 «El militar profesional -escribe Francisco LAGUNA SANQUiRico (en «El militar ante la guerra», en Reconquista, núm. 390, enero 1983, p. 38)-, a la par que recibe una formación técnica, aprende en las Academias Militares un código ético y moral que es consustancial con su vocación y sin el que pasaría a poderse considerar más como un guerrero que como un soldado. Esto es así, y en todas las FAS del mundo moderno la tendencia es incidir en este rango de la "ética".»

${ }_{107}$ Miguel Alonso Baquer, «La peculiaridad del sistema militar de educación», en Reconquista, núm. 395, junio 1983, p. 40. 
cado sobre una retórica y sobre una estética. $\mathrm{Y}$ es cierto que un entorno de grandes palabras y bellas imágenes ha logrado constituirse sólidamente en obligado acompañante de la primera enseñanza militar. Una verdadera liturgia con fondo musical empuja con bien dosificada frecuencia hacia el comportamiento noble y hacia el sentimiento elevado. $\mathrm{Y}$ nadie piensa en prescindir de ella. De ahí que si bien se pueden detectar cambios en el contenido de los planes de estudio e incluso se han liberalizado las costumbres, la estructura del género de vida que se considera ajustado a la formación del futuro militar tiende a la permanencia.

No le falta razón al autor anterior cuando justifica la necesidad de conjunción de una retórica y de una estética en la metodología didáctica de las Academias y Escuelas Militares. En cuanto ello contribuye a potenciar los más elevados sentimientos de los educandos, es a todas luces positivo. Ahora bien, resultan preocupantes las diferencias cualitativas con, por ejemplo, la enseñanza universitaria, pues, como en otro lugar reseña el mismo Alonso Baquer ${ }^{108}$, esa divergencia puede incidir en la deseable homogeneidad de los sentimientos de todos los componentes de una comunidad histórica. Puede admitirse, desde luego, que se entienda positiva la práctica de las Academias de insuflar en los futuros oficiales un sentimiento de identidad corporativa e institucional a través de un género de vida similar al de los tiempos de conflagración bélica. Sin embargo, ello tiene un límite evidente: a través de tales peculiaridades lo que no puede en modo alguno pretenderse es perfilar un estamento segregado del común de los ciudadanos; bien al contrario, a las Academias corresponde formar unos oficiales que se integren estrechamente en la sociedad de la que es obvio que forman parte y a la que deben defender en tiempos de peligro.

Esa ineludibilidad de que la enseñanza militar provea oficiales plenamente integrados en nuestra sociedad es lo que ha puesto en movimiento en España la cuestión de la reforma de la enseñanza superior militar.

En 1984, en un Seminario sobre Enseñanza Militar organizado por la Escuela Superior del Ejército, el general Cano Hevia se hacía eco de la imperatividad de la modernización en este trascendental campo: «La modernización es necesaria en el sentido de puesta al día. El proceso humano no se detiene, y la enseñanza tiene que seguirle e incluso preverle. Hay que dar un salto adelante, hay que analizar y modificar sistemas, programas y hábitos didácticos; y hay que hacerlo revisando prejuicios y con la necesaria progresividad y prudencia para que las buenas intenciones no se traduzcan en confusión inoperante» ${ }^{109}$.

En un informe sobre la reforma de la enseñanza militar en España, hecho

${ }^{108}$ Miguel Alonso Baquer, «El estilo militar de vida», en Reconquista, núm. 395, junio 1983 , p. 41.

${ }^{109}$ Cit. por José M. ${ }^{a}$ Riaza Ballesteros, Líneas generales de la reforma de la ensenanza militar, op. cit., p. 2. 
público - bien que a nivel reservado- en junio de $1984^{110}$, se proponía una estructura más idónea para las diferentes áreas de estudio (militar, técnicocientífica, humanística y preparación física), recomendándose el régimen de internado como medio idóneo para desarrollar las virtudes militares y como un límite para el acceso de otras corrientes, y sugiriéndose que la enseñanza de la moral militar tenga como guía las Reales Ordenanzas, debidamente actualizadas ${ }^{111}$. «El código moral de los militares españoles - se lee en el citado documento- deberá estar abierto a los valores que se van incorporando por la sociedad en su continua evolución, sin que ello suponga que deban asumirse todas las modas cambiantes de la sociedad.»

En esta dirección, parece importante, como sostiene Arteaga ${ }^{112}$, la interdisciplinariedad de la reforma. Es imprescindible que la enseñanza superior militar proyecte su reforma en coordinación con la reforma del modelo de enseñanza que se desarrolla en la sociedad. La autarquía debe replantearse y, aun cuando ésta pueda darse en algunos supuestos, se deben considerar los mismos como una especialidad del sistema general de enseñanza. En esta modernización de la enseñanza militar es evidente que deben colaborar todos aquellos sectores sociales universitarios, industriales o científicos implicados. No es posible en una sociedad como la nuestra, con recursos económicos, técnicos y humanos tan escasos, dividir esfuerzos, duplicar docencias y aislar experiencias. De ahí que la autosuficiencia sea de todo punto imposible en una función interdisciplinar cual requiere la actividad castrense.

En definitiva, como se ha subrayado con evidente razón ${ }^{113}$, la educación cívica del militar de nuestro tiempo ha de incluir el estudio de todas las realidades sociales, por muy diferentes que aparezcan de sus propias vivencias y conceptos. El oficial de nuestros días debe renunciar a la autoridad del discurso, característica de toda institución, y aceptar en lo social la discusión. $\mathrm{La}$ indiferencia ante la realidad social sería la resultante lógica de su desconocimiento; ello encerraría al militar en sí mismo, convencido de la legitimidad de su saber. En una situación de este tipo resultaría utópica su integración en una sociedad multiforme y pluralista que, en el ámbito del saber, viene caracterizada por la ruptura y fragmentación de los conocimientos.

Un sistema educativo que se enderece hacia esa meta ideal propiciará la integración social de los profesionales de las armas, quebrando así con la tradicional vertiente aislacionista que históricamente ha venido teniendo la enseñanza militar. Esta orientación hacia la sociedad no significa en modo alguno

${ }_{110}$ BIRDS (Boletin Informativo Reservado sobre Defensa y Seguridad), Madrid, junio 1984.

11 Anselmo Santos, La educación cívica de los militares desde los esquemas clásicos a la postmodernidad, ponencia presentada al II Congreso de Sociología, Santander, 1984, p. 22.

112 Félix ARteaga Martín, La enseñanza militar: estructuras de cambio y cambio de estructuras, ponencia presentada al II Congreso de Sociología, Santander, 1984, p. 8.

${ }^{113}$ Anselmo Santos, La educación cívica de los militares..., op. cit., pp. 24-25. 
un olvido del código ético de la institución, de las virtudes peculiares de los Ejércitos; éstas deben ser preservadas, puesto que contribuyen a perfilar la esencia de la institución, al margen de que los Ejércitos no pueden pretender asumir las modas cambiantes de la sociedad; sin embargo, ese «ethos militar» debe hacer suyos los grandes valores sociales que en cada circunstancia histórica el conjunto de la sociedad hace suyos de modo indubitado.

Se impone, pues, como manifiesta Prudencio García ${ }^{114}$, el mantenimiento de lo permanente, pero con la añadidura de nuevas y grandes exigencias. Bien es verdad que no se trata exclusivamente de abarcar una amplia gama de conocimientos militares, sino de poseer una formación integral que, desbordando forzosamente el ámbito de lo estrictamente castrense, se sitúe en un plano suficientemente elevado sobre él como para permitir determinar en qué sentido deben producirse las innovaciones pertinentes, alterarse las enseñanzas y modificarse los comportamientos. Resulta, pues, evidente - significa el propio autor ${ }^{115}$ - que al oficial profesional de mañana no habrá de bastarle con saberse su correspondiente técnica militar. Por supuesto que tal conocimiento es y seguirá siendo requisito imprescindible. Pero, dando por sentada su competencia técnica, ésta no habrá de bastarle por sí sola. Siendo el mando una función esencialmente moral de convicción, influencia, apoderamiento y captación del ánimo y la voluntad de otras personas, estos resultados jamás podrán alcanzarse sin un determinado nivel humano por parte de quien lo ejerce. En resumen, el militar de carrera está llamado a ser un profesional de elevadísimo nivel, menos numeroso en cantidad, pero altamente seleccionado en calidad, integrando en sí mismo ciencias tan dispares como las técnicas y las humanas ${ }^{116}$.

\section{Ideología militar y corporativismo}

La ideología de los Ejércitos es un fenómeno de difícil análisis, tanto por su carácter polifacético como por los complejos factores que inciden en su desarrollo ${ }^{117}$.

Credos, doctrinas, opiniones y valores son, según Van Doorn ${ }^{118}$, los elementos determinantes para la caracterización de este fenómeno social. Es obvio que ninguna organización se sitúa en el vacío; por contra, todas se encuen-

${ }^{114}$ Prudencio García, Ejército: presente y futuro, vol. 1: «Ejército, polemología y paz internacional», Alianza Editorial, Madrid, 1975, pp. 230-231.

${ }_{115}$ Prudencio García, Ejército: presente y futuro, op. cit., p. 233.

116 Ibidem, p. 238.

${ }^{11}$ Cfr., al respecto, la exposición, cuyas líneas generales en parte hemos seguido, de Jorge Silva Ortiz (y otros), Democracia y Fuerzas Armadas, Institute for the New Chile, Rotterdam, 1979.

${ }_{118}$ Jacques vaN DooRN, «Ideology and the Military», en Morris Janowitz y J. VAN Doors (eds.), On Military Ideology, Rotterdam University Press, Rotterdam, 1971, pp. XIII y ss. 
tran rodeadas por la contingencia del núcleo humano del cual forman parte; de ahí que su modo particularizado de pensar, su ideología, esté condicionada por múltiples factores que se extienden desde los particularmente profesionales hasta los sociales y políticos que penetran la estructura orgánica.

Pues bien, partiendo de estas premisas, se puede considerar que el complejo de credos, doctrinas, valores y opiniones que se reflejan en el interior de las FAS y la forma en que se proyectan hacia nuestra sociedad, persiguiendo su protección y desarrollo, constituyen la ideología de las FAS.

Van Doorn ha visualizado tres tipos de ideologias en las Fuerzas Armadas: a) la ideología política; b) la ideología corporativa o profesional, y $c$ ) la ideología operativa. $\mathrm{Y}$ a ellas nos referiremos de inmediato.

A) La ideología política. No se genera esta ideología en el interior de los cuarteles, sino que es una proyección de concepciones ideológicas normalmente sustentadas por elementos ajenos al quehacer militar, pero que expresan la dinámica común de toda sociedad.

Estas concepciones ideológicas penetran de modo preferente a nivel de los altos mandos institucionales, diseminándose hacia el interior de las FAS por los conductos regulares que rigen el mecanismo de transmisión de órdenes.

Contrasta esta presunta ideología política con la tradicional consideración apolítica del instituto armado ${ }^{119}$, que deviene de una premisa de su actuación, consolidada en el pasado siglo: la absoluta carencia de iniciativa de los Ejércitos, su imposibilidad de deliberar y su total subordinación al legítimo poder civil establecido, subordinación que, rememorando un tanto a Vigny ( «El Ejército -escribirá el gran novelista francés ${ }^{120}$ - es mudo y ciego. Golpea delante de él allí donde le ponen. No quiere nada por sí y obedece por resorte»), hará merecer al Ejército francés de la III República el apelativo de la grande muette.

El postulado de la apoliticidad de los cuerpos armados deriva, pues, de su subordinación al poder civil e implica la imposibilidad de que el Ejército adopte una postura política.

Ahora bien, se ha afirmado ${ }^{121}$, no sin razón, que el apoliticismo se encuentra en franca crisis en la actualidad, crisis iniciada básicamente tras la segunda gran guerra. Sin embargo, creemos preciso de inmediato concretar el sentido exacto de esa crisis.

Desde luego, es claro que el principio de no intervención en la vida política interna sigue teniendo pleno vigor. Como al efecto apunta Lider ${ }^{122}$, «military force does not intervene in domestic policy; it is politically neutral or apolitical. This was tantamount to the proposition that military force has

19 Hermann Oe h LiNg, La función política del Ejército, op. cit., pp. 90 y ss.

${ }^{120}$ Alfredo DE VIGNY, Servidumbre y grandeza militar, op. cit., p. 18.

121 Hermann OE H LING, La función política..., op. cit., p. 96.

${ }_{122}$ Julian LIDER, British Military Thought after world war II, Gower Publishing Company Limited, Aldershot (Inglaterra) y Brookfield (Vermont, USA), 1985, p. 84. 
no domestic function, except that of intervening during the gravest emergency in order to salvage the system which has been approved by the whole nation».

Resulta claro, en consecuencia, que la crisis del apoliticismo no puede ser explicada en base a la necesidad de una intervención en la política interna. La explicación del real significado del rechazo actual del apoliticismo de los Ejércitos habrá que buscarla en la distinción entre «apartidismo» y «apoliticismo». Prudencio García ${ }^{123}$ resume así la clave de la cuestión: sí al apartidismo estricto; no al apoliticismo ciego.

El hecho de que el militar conserve celosamente su no vinculación a ningún grupo político determinado - señala el autor precitado en un momento posterior ${ }^{124}$-, teniendo siempre muy presente que sus misiones se sitúan en un plano muy superior al de todo grupo, asociación o partido, no debe servir de motivo, ni mucho menos de justificación, para hacerle caer en el extremo opuesto - no menos inadmisible - de un apoliticismo entendido como inhibición absoluta que le condujese a la más garrafal ignorancia de toda problemática social y política.

Es evidente que el mejor modo de evitar el peligro de esta inhibición es la madurez política e ideológica ${ }^{125}$, que no implica forzosamente la adscripción a una determinada ideología. Madurez entraña, en su más exacto sentido, todo lo contrario de una falsa solidez de conceptos basada en su ingenua simplificación. Política, una vez alejado el ancestral recelo que esta palabra despertó en el militar de otras épocas, ya superado por la actual mentalidad castrense, que incluye a la cultura, y por ende, entre otros, el conocimiento político, como uno de los pilares básicos de la misma.

En este orden de consideraciones, se ha significado ${ }^{126}$ que un ejército apolítico sería un ejército en situación de «indefensión ideológica», que permite su rápida politización en favor de cualquier ideología que se le imponga. Un ejército en tal situación difícilmente podrá ser el último garante del régimen democrático ${ }^{127}$.

No muy distante de las anteriores es la posición que sustenta el general Díez Alegría ${ }^{128}$, para quien el que el militar profesional sea apolítico no quiere decir, pues ello resultaría hasta monstruoso, que como individuo no sienta preocupaciones por la dirección de su país y hasta deje de experimentar mayor

${ }^{123}$ Prudencio GaRcía, Ejército: presente y futuro, op. cit., p. 12.

124 Ibidem, p. 34.

${ }^{125}$ Ibidem, pp. 227-228.

126 Julio BusQueTs, El militar de carrera..., op. cit., p. 227.

${ }^{127}$ Precisamente, en España ha sido el mantenimiento del principio de neutralidad política de la institución armada una de las razones básicas que en su día condujo a las restricciones del ejercicio de ciertos derechos de participación política por parte de los militares, lo que es rechazado por ciertos sectores doctrinales. Cfr., al efecto, Tomás BuIzA Cortés, «Los militares y el derecho a la participación política», en Sistema, núm. 63, noviembre 1984, pp. 133 y ss.

${ }^{128}$ Manuel Díez Alegría, Ejército y Sociedad, Alianza Editorial, Madrid, 1972, páginas $50 \mathrm{y}$ ss. 
o menor simpatía por una u otra de las ideologías que se debaten en el campo político. Lo que no puede hacer es sustentar estas teorías apoyándose en su condición de oficial, y mucho menos hacerlas prevalecer reunido con sus compañeros como expresión del pensamiento del Ejército. Es bien visible, en consecuencia, que el apartidismo, de todo punto necesario, no puede confundirse con el apoliticismo.

Es preciso subrayar, finalmente, que la responsabilidad moral de los Ejércitos ante la comunidad nacional debe imposibilitarles la sistemática abstención intelectual y social, pero para lograr tal finalidad no basta con la profesionalidad - con ser ésta un factor coadyuvante ${ }^{129}$ - ni tampoco resulta suficiente la orientación de los profesionales de la Milicia en esa dirección; es, además, precisa la mutua colaboración entre los miembros de la institución armada y las fuerzas y grupos sociales y políticos. Son significativas a este respecto las dos razones que se aducen para explicar el carácter apolítico de las Fuerzas Armadas del Reino Unido. A juicio de Brown ${ }^{130}$, el carácter apolítico de las FAS británicas es, según opinión generalizada, el resultado de una doble circunstancia: a) de una clara tendencia de los partidos políticos británicos a alejar a los militares de la política interna, impidiéndoles intervenir en los asuntos interiores salvo durante las más graves emergencias, y b) de la propia organización institucional de las FAS, desfavorable a la posibilidad de un colectivo político ansioso de tener una misión política propia y, más aún, de una discusión activa acerca de las diversas facetas de la vida política, o de una participación de los miembros del colectivo en actividades políticas.

B) La ideología corporativa. Es ésta una ideología que, a juicio de Van Doorn, a la par que justifica la subordinación de un grupo humano a la disciplina castrense, produce un mecanismo de autodefensa de la corporación, basado en la tradición, la historia, los valores ético-profesionales junto a las manifestaciones propias que genera el ceremonial militar.

Parece algo comprobado, como advierte Gutteridge ${ }^{131}$, que la disciplina crea cohesión y un sentido real de espíritu de cuerpo. Abrahamsson ${ }^{132}$, a este respecto, manifiesta que, en mayor medida que otras profesiones, la profesión militar refuerza la cooperación, la camaradería y la cohesión grupal. Janowitz ${ }^{133}$ estima que la detallada regulación con que se contempla en las orde-

${ }^{129}$ Cfr., al respecto, Gene E. BIGLER, «La restricción política y la profesionalización militar en Venezuela», en Politeia, Instituto de Estudios Políticos, Caracas, 1972, pp. 85 y ss.; en especial, pp. 91-92.

${ }_{130}$ Neville Brown, «The evolution of British Strategic Thought», en Horton, Rogerson y Warner (eds.), Comparative Defence Policy, The John Hopkins University Press, Baltimore y Londres, 1974, pp. 233-234.

${ }_{131}$ William GuTTERIDGE, Military Institutions and power in the new nations, Pall Mall Press, Londres y Dunmow, 1964, p. 47.

${ }_{132}$ Bengt Abra hamsSon, «La socialización profesional: teoría, ética y espíritu de cuerpo», op. cit., p. 221.

${ }^{133}$ Morris Janowitz, The Professional Soldier..., op. cit., p. 175. 
nanzas militares el estilo de vida militar viene exigida para intensificar la cohesión grupal, a la vez que la lealtad y el espíritu marcial. Y Huntington ${ }^{134}$ conecta la ética militar no con el individuo, sino con la colectividad o corporación militar en su conjunto: «The military ethic — señala Huntington- is basically corporative in spirit. It is fundamentally anti-individualistic.»

Más aún, uno de los rasgos con los que Huntington distingue a los militares modernos de aquellos otros anteriores a la Revolución Francesa de 1789 es la existencia de un espíritu corporativo (los otros tres rasgos son: la capacidad técnica, la relación de dependencia frente a su cliente, esto es, frente al Estado, y la mentalidad militar); pues bien, Perlmutter ${ }^{135}$ cree demostrado que, de las cuatro variables anteriores, dos de ellas, la mentalidad militar y «the corporate spirit», entendido este último fenómeno como «collective selfconfidence and intragroup competitiveness» ${ }^{136}$, son de notoria mayor relevancia que las otras dos.

En otro orden de consideraciones, cabe significar que la corporación militar ha tendido a ejercer un control total sobre el modo de vida, incluso priva$\mathrm{da}$, de sus miembros, incluyendo en ello desde su vestimenta hasta la autorización para contraer matrimonio. Ello ha generado un microcosmos, una especie de autarquía que se expresa en una panoplia de símbolos, de los que, posiblemente, el primero venga dado por el respeto hacia la propia jerarquía. El «más antiguo", el de mayor graduación «tiene siempre la razón», porque lleva distintivos superiores, porque es el símbolo de la superioridad. Buen paradigma de lo que acabamos de señalar puede constituirlo la siguiente consideración de Vigón ${ }^{137}$ : «El hombre inteligente no renuncia en el Ejército a la facultad de discurrir. Obedece, y obedece ciegamente, por razonamiento en el que no entra para nada el temor al castigo...» Es obvio que no se comprende del todo bien cómo la obediencia puede a la vez ser ciega y razonada.

Ahora bien, en nuestros días se va hacia un nuevo concepto de disciplina ${ }^{138}$. Prudencio García, con absoluta claridad, nos da las razones de ello. La evolución de las sociedades actuales y el acceso del hombre moderno hacia niveles más elevados de conocimiento, cultura y dignidad han ido produciendo en los círculos militares de los países occidentales más avanzados una tendencia, cada vez más acusada, hacia una matización del concepto de disciplina, incorporando a ésta una mayor dosis de responsabilidad individual y de iniciativa personal, en detrimento -más bien cabría decir en superación- de un concepto de obediencia ciega y absolutamente automática que, llevada a su extremo, reduciría al hombre a la condición de mero «robot» ejecutor. Recor-

${ }^{134}$ Samuel P. Huntington, The soldier and the State..., op. cit., p. 64.

${ }^{135}$ Amos Perlmutter, The Military and Politics in modern times, op. cit., p. 9.

${ }^{136}$ Ibidem, p. 36.

${ }^{137}$ Jorge VIGóN, «El espíritu militar español», op. cit., en la obra de Ediciones Ejército, p. 238.

${ }_{138}$ Cfr., al respecto, Prudencio García, Ejército: presente y futuro, op. cit., pp. 191-204. 
demos al efecto que ya Janowitz ${ }^{139}$, al analizar la evolución de la institución armada desde el fin de la guerra hasta hoy, se referiría como uno de los rasgos más significativos de los cambios generados en la institución al «changing organizational authority», esto es, al cambio en las bases de la autoridad y la disciplina, mutación que viene dada por un paso de «an autoritarian domination to greater reliance on manipulation, persuasion and group consensus».

Retornando al corporativismo, diremos que Abrahamsson ${ }^{140}$ ha considerado el espíritu corporativo como la resultante de varios factores que, en esencia, son los que siguen: a) el largo período de educación académica; $b$ ) los códigos de conducta, los rituales y los símbolos relacionados con las tradiciones internas; c) la existencia de medios de comunicación de contenido altamente especializado; d) un sistema de rotación entre funciones de asesoramiento y de mando, y e) las recompensas profesionales.

Es verdad que se ha hablado de una crisis del corporativismo (y con ello de la ideología que entraña) por mor de la revolución profesional ${ }^{141}$, pero no es menos cierto, como significa Perlmutter ${ }^{142}$, que «modern professionalism is corporate; that is, it includes group consciousness and a tendency to form corporate professional associations», y que «the military profession is an outstanding example of modern corporate professionalism».

La ideología corporativa, a diferencia de la política, es autogenerativa, esto es, surge en el seno de la propia comunidad militar, bien que, desde luego, se vea afectada por la introducción de ideas o ideologías del grupo social, por lo menos de aquellas que no se contrapongan a ciertas concepciones internas propias de una mentalidad, como ha señalado Huntington ${ }^{143}$, realista y conservadora ${ }^{144}$.

Precisamente será esta orientación corporativa la que propiciará el aislamiento social del instituto armado. El intento de conservar su carácter autárquico se materializará, probablemente, en presiones políticas de tipo orgánico; de otro lado, al ser la organización financiada por el Estado, tendrá un interés económico en la continuidad de sus funciones; al devolver al Estado un servicio trascendental, pero cuyo valor no puede ser tasado en términos pecuniarios, la cuenta será siempre correcta para los militares, pero seguramente criticada por ciertos sectores civiles; la reacción será la voluntad de autodefensa y el aislamiento de la corporación castrense.

${ }^{139}$ Morris Janowitz, The Professional Soldier..., op. cit., pp. 7 y ss.

140 Bengt ABRa HAMsSon, «La socialización profesional...», op. cit., pp. 222-223.

141 Amos Perlmutter, The Military and Politics in modern times; cfr., en especial, pp. $30-35$.

${ }_{142}$ Amos Perlmutter, The Military and Politics..., op. cit., pp. 32-33

${ }^{143}$ Samuel P. Huntrngton, The soldier and the State..., op. cit., p. 79.

144 Para Perlmutter (en The Military and Politics..., op. cit., p. 31), la autonomía que el cuerpo de oficiales obtuvo con la revolución profesional potenció aún más el conservadurismo corporativo y político de los militares, al aislarlos de la comunidad política. 
C) La ideología operativa. Van Doorn se ha referido a cómo las Fuerzas Armadas aún se siguen justificando en su existencia en base a su capacidad para emplear la violencia, capacidad que ocasiona esta «ideología operativa» que se considera ${ }^{145}$ parte fundamental de esa particular forma de cultura que se define como «ethos militar».

Ante situaciones concretas en que puedan verse involucradas, las FAS crean la existencia de un «enemigo» como justificación de su acción; ello da pie al desarrollo de este tipo de ideología, destinada a motivar a sus componentes para neutralizar, repeler o destruir a aquel enemigo. La ideología operativa aparece así como la racionalización y justificación ética del tipo de acciones $\mathrm{u}$ operaciones destinadas a enfrentar y liquidar al enemigo. Como han significado Harries-Jenkins y Moskos ${ }^{146}$, la cuestión que esta ideología suscita para el oficial individual es la del posible conflicto entre su ideología «operativa», justificada en términos de éxito militar, y su ideología «civil», legitimada en función de su habilidad administrativa, problemática que, a su vez, conecta con la contradicción entre el modo de vida militar tradicional y la organización tecnológica altamente especializada que se requiere en la actualidad.

En todo caso, de esta ideología operativa pueden resultar aspectos positivos y negativos en la conducta del soldado, pues es obvio que puede conducir a la nobleza del combatiente, llevarlo a actos de heroísmo, desprendimiento, respeto del adversario incluso, o, todo lo contrario, puede dar paso a los crímenes de guerra.

\section{La trascendente finalidad de los Ejércitos}

Se ha dicho, con razón, que la defensa es el fin primario del Estado. Precede a cualquier otra función o fin. La seguridad de la comunidad produce la tranquilidad y orden necesarios para acometer los fines propuestos por el Estado ${ }^{147}$.

Pues bien, parece no ofrecer resquicio alguno a la duda que los Ejércitos, en su concepto un tanto primario ${ }^{148}$ de violencia organizada al servicio de la comunidad, son quienes deben prístinamente asumir la función de defensa. «The modern military establishment — dirá Perlmutter, en semejante dirección ${ }^{149}$ - patterned its organizational structure after that of the nation-state, and its corporate orientation was designed to perpetuate and preserve the nation-state's integrity.»

En definitiva, preservar la integridad de la comunidad en que se imbrican;

${ }^{145}$ Gwyn Harries-Jenkins y Charles C. Moskos, Jr., Las Fuerzas Armadas y la Sociedad, Alianza Universidad, Madrid, 1984, p. 57.

${ }_{146}$ Ibidem, p. 57.

147 Hermann OE H LING, La función política del Ejército, op. cit., p. 39.

${ }^{148}$ Manuel Díez Alegría, Ejército y Sociedad, op. cit., p. 14.

149 Amos Perlmutter, The Military and Politics in modern times, op. cit., p. 35. 
tal ha sido la trascendental misión de los Ejércitos. De ello ya se deduce inequívocamente que no cabe la identificación entre Ejército y guerra; el Ejército es el medio de hacer la guerra, de conseguir la defensa, pero su fin no es tanto hacer la guerra cuanto prevenirla, evitarla ${ }^{150}$.

Frente a los cuestionamientos que se han efectuado acerca de si hoy existen verdaderamente amenazas que justifiquen la permanencia de los Ejércitos, se ha puesto de relieve ${ }^{151}$ que la guerra es una realidad tangible, una presencia amenazante que aparece como una constante histórica. Nada nos permite aventurar hoy que el fenómeno bélico esté en trance de desaparición, bien que sí pueda hablarse de distintas modalidades de conflicto. La amenaza de cualquiera de ellos justifica por sí la necesidad defensiva de las sociedades organizadas, que encomiendan su defensa a los Ejércitos, sin que éstos sean otra cosa que un instrumento, una herramienta cualificada para llevarla a cabo, pues la responsabilidad será siempre del Estado, en tanto en cuanto serán los órganos representativos de la comunidad nacional quienes deban adoptar las decisiones pertinentes que habrán de ejecutar los Ejércitos.

En otro orden de consideraciones, cabe significar que las modernas manifestaciones de la guerra (fría, revolucionaria, psicológica, convencional, atómica...) han propiciado nuevos conceptos sobre la defensa nacional. En síntesis, podríamos decir que hoy es comúnmente admitido que la defensa no es algo exclusivo de los militares; su actual naturaleza atiende a todos los factores aptos de la nación. Puede, pues, afirmarse, con el general Guerin ${ }^{152}$, que «la defensa descansa fundamentalmente sobre el poder militar y humano de la nación». De ahí precisamente que hoy la finalidad trascendente de los Ejércitos, la defensa de la comunidad, haya dejado de ser un elemento que, por sus específicas características, actuaba más como factor de aislamiento que como impulsor de la integración social.

No podemos ignorar en modo alguno - diremos, haciendo un breve excursus - que modernamente la idea de seguridad nacional (íntimamente conectada con la de defensa, en una relación entre ésta y aquélla de medio a fin), que es, sin duda, uno de los conceptos más importantes y trascendentes de los que impulsan la vida nacional, pues en él se fundamenta en buena medida

${ }^{150}$ Juan AREncibia (en «En el Ejército no se enseña a matar», en Reconquista, número 391 , febrero 1983 , p. 53) hace las siguientes reflexiones: "La finalidad de los ejércitos es preparar a los hombres que los constituyen para defender, llegado el caso, a la Patria, incluso con la ofrenda de sus vidas cuando fuera necesario. La actuación por la fuerza de las armas es una eventualidad y no depende de nosotros solos el evitarla. La preparación para el combate de los hombres que se encuentran en las filas de las FAS es una necesidad ante tal eventualidad. La existencia de las FAS manifiesta la voluntad de una nación para mantenerse soberana y en paz.»

${ }^{151}$ Equipo R, «Fuerzas Armadas, ¿para qué?», en Reconquista, núm. 375, septiembre 1981, pp. 10-11.

152 General Guerin, «Les aspects scientifiques et techniques de la Défense Nationale», en La Défense Nationale, Université d'Aix-Marseille, PUF, París, 1958, p. 397. Cit. por Hermann OE hling, La función política..., op. cit., p. 64. 
la garantía de la identidad y permanencia de la nación ${ }^{153}$, ha dado pie a la «doctrina de la seguridad nacional» ${ }^{154}$, que, aunque tiene su origen en una teoría ampliamente desarrollada en los Estados Unidos, la teoría de las FAS como nation-building, como constructoras de la nación ${ }^{155}$, se ha aplicado a países en vías de desarrollo, implicando en esencia una participación permanente de los militares en el control del aparato político-estatal ${ }^{156}$, lo que retrotrae a los Ejércitos a situaciones ya periclitadas en las sociedades occidentales y, en todo caso, muy distantes de las condiciones necesarias para que pueda hablarse de una integración social de los mismos. El eufemismo con que se intentará justificar la doctrina será la falta de preparación de las nuevas naciones para el gobierno democrático ${ }^{157}$.

Retornando nuevamente al hilo central de nuestra argumentación, cabe decir que la integración social de las FAS, en cuanto se refiere al factor que comentamos, ha venido propiciada no sólo por esa nueva concepción de la defensa nacional, sino también por una serie de nuevas funciones que ha venido a asumir la institución armada respecto de la comunidad social.

Con respecto, por ejemplo, a los nuevos Estados, Janowitz ${ }^{158}$ ha subrayado la particular importancia de las funciones no militares de los militares, que se han perfilado como agentes del cambio social y político ${ }^{159}$. Gutteridge ${ }^{160}$, por su lado, estima que las FAS de los Estados recientemente independizados se han convertido en instituciones sociales y políticas de primer orden, teniendo a veces un inmediato papel educacional en la sociedad, encontrándose por lo común del lado de la modernización social ${ }^{161}$.

También en nuestro país se ha considerado al Ejército como un agente de

${ }^{153}$ Cfr., al respecto, F. Quero, «La idea de seguridad nacional», en Reconquista, número 416, julio-agosto 1985 , pp. 9-11.

154 Cfr., en torno al tema, Joseph Combin, El poder militar en América Latina, Ediciones Sígueme, Salamanca, 1978 , pp. 125 y ss.

${ }^{155}$ Cfr., al efecto, Karl W. Deutsc $\mathrm{H}$ y William J. Foltz (eds.), Nation-Building, Atheton Press, Nueva York, 1963. Asimismo, Raymond Moore, Jr., "The Paceful Uses of Military Forces in Underdeveloped Areas: a Review Essay», en The Journal of Developing Areas, vol. 4, 1969-1970, publicado por Western Illinois University.

156 Jorge TAPIA VALDÉs, La doctrina de la seguridad nacional y el rol político de las Fuerzas Armadas, Institute for the New Chile, Rotterdam, 1979, p. 9.

${ }^{157}$ Cfr., al efecto, Lucien W. PyE, Aspects of Political Development. An Analytical Study, Little Brown and Co., 1966, pp. 87-88.

${ }^{158}$ Morris Janowitz, The Military in the Political Development of New Nations. An essay in comparative analysis, The University of Chicago Press, Chicago, 1964, p. 31.

${ }_{159}$ Cfr., al respecto, John J. Jo Hnson, The role of the military in underdeveloped countries, Princeton University Press, Princeton, 1962, pp. 3 y ss.

${ }^{160}$ William GutTerIDge, Military Institutions and power in the new States, op. cit., p. 176.

161 Eric NordLINGer (en «Soldiers in mufti: the impact of military rule upon economic and social change in non-western states», en American Political Science Review, 64, 1970, pp. 1131 y ss.), por el contrario, es de la opinión de que los gobernadores militares se encuentran esencialmente distantes del cambio social en las sociedades en vías de desarrollo. 
acción social ${ }^{162}$. Díez Alegría ${ }^{163}$, tras considerar como primer deber de las FAS el de constituir el medio coactivo del Estado, la fuerza organizada a disposición de la comunidad, estima que también les corresponde el deber histórico de ser guardián de las tradiciones y valores nacionales, así como otros deberes de carácter menos militar, entre los que hay que destacar: el deber político de estar al servicio del Estado incondicionalmente, por encima de todas las parcialidades y deseos de poder, y el deber social y económico de contribuir a la atención de los sectores más necesitados, de participar dentro de su escala en el desarrollo del país, idea esta última que recoge de Orsolini ${ }^{164}$.

Se ha subrayado, asimismo, fuera de nuestras fronteras el papel formativo de las FAS ${ }^{165}$, que se relaciona con la resocialización de los adolescentes, al dárseles una segunda oportunidad para su educación y formación.

Si efectuamos una reconsideración final, podemos advertir cómo las diversas misiones que hoy cumplen los Ejércitos pueden - y deben- subsumirse en una específica vocación de servicio a la comunidad.

Profundizando en esta última reflexión, y ya con una referencia específica a España, podemos recordar cómo en el plano legal está inequívocamente contemplada esta vocación de los Ejércitos. En efecto, el artículo 2. ${ }^{\circ}$ de la Lev $85 /$ 1978, de las Reales Ordenanzas de las FAS, estipula:

«Bajo el mando supremo del Rey, las Fuerzas Armadas, constituidas por el Ejército de Tierra, la Armada y el Ejército del Aire, están exclusivamente consagradas al servicio de la Patria, quehacer común de los españoles de ayer, hoy y mañana, que se afirma en la voluntad manifiesta de todos.»

Y el artículo $4 .^{\circ}$ refuerza esta idea cuando se refiere a que «las Fuęrzas Armadas, identificadas con los ideales del pueblo español, del que forman parte, al que sirven y del que reciben estímulo y apoyo». Esta declaración, dirá Martín Jiménez ${ }^{166}$, elimina cualquier rescoldo sobre apartheid, gheto o «casta», que algunas mentes todavía albergan respecto a los Ejércitos. Y, desde luego, la categórica declaración inicial del artículo $2 .^{\circ}$ constituye la respuesta radical del ser esencial de los Ejércitos ${ }^{167}$.

Es cierto que podrá aducirse que la «regla moral de la Institución», que ilumina a los militares con su doctrina, mezcla de lo viejo e imperecedero con

162 Angel González de Mendoza y Dorvier, «El Ejército como clase social. Su labor educadora y ciudadana», en el colectivo La Milicia como tema de nuestro tiempo, Ediciones Cultura Hispánica, Madrid, 1955, pp. 75 y ss.; en concreto, p. 100.

${ }^{163}$ Manuel Díez Alegría, Ejército y Sociedad, op. cit., pp. 49-50.

164 Mateo Horacio Orsolini, Ejército argentino y crecimiento nacional, Ediciones Arayú, Buenos Aires, 1965.

${ }_{165}$ Gwyn Harries-Jenkins y Charles C. Moskos, Jr., Las Fuerzas Armadas y la Sociedad, op. cit., p. 83.

${ }^{166}$ Hilario Martín Jiménez, Los valores morales..., op. cit., p. 88.

${ }^{167}$ En análogo sentido se pronuncia Hilario MARTín JimÉnez, Los valores morales..., op. cit., p. 85 . 
lo nuevo que merece ser incorporado al acervo espiritual de los Ejércitos ${ }^{168}$ se limita, como ha señalado Ollero ${ }^{169}$, a una reiterada e hiperbólica consagración de una serie de principios y valores que se orientan a configurar un especial «espíritu», una singular fisonomía antropológica, un catálogo referencial y modélico de pautas de comportamiento, con lo que las Ordenanzas bien podrían ser tildadas más como un catálogo orientador, como «un ideal» a seguir, que como un auténtico código positivo de normas a cumplir. Pero-lo cierto es que, al margen ya de cualquier valoración positiva y dejando a un margen, asimismo, el hecho incuestionable de que ${ }^{170}$ todos y cada uno de los artículos de las Ordenanzas forman una trama que, en su conjunto, define cómo debe ser el militar español, la realidad nos muestra cómo esa «vocación de servicio» es, por lo general, asumida por los integrantes de nuestros Ejércitos.

De otro lado, el espíritu de servicio es elevado a un primer plano dentro de la ética militar. Son numerosísimas las referencias al mismo que encontramos en el pensamiento militar reciente ${ }^{171}$.

El servicio no aparece como una razón o motivo per se, ya que no se trata de sacrificarse porque sí; bien al contrario, se trata de una actitud llena de contenido, precisamente porque viene exigida por el cumplimiento de un deber; en definitiva, de una misión: la defensa de la voluntad nacional ${ }^{172}$, pues, como dijera S. M. don Juan Carlos I en su discurso dirigido a los Ejércitos con motivo de la Pascua Militar de $1982{ }^{173}$, si los Ejércitos pueden poseer un pensamiento propio, su voluntad no puede ser otra que la de la nación.

Es claro por todo lo dicho que el espíritu o vocación de servicio a la co-

168 Hilario Martín JimÉnez, Los valores morales..., op. cit., p. 11.

169 Carlos Ollero, «Constitución y Reales Ordenanzas», en Primeras Jornadas Fuerzas Armadas-Universidad, Madrid, febrero 1982 (CESEDEN), pp. 221 y ss.; en concreto, p. 226.

${ }^{170}$ Miguel Ruiz Nicolau, «Comentarios a las Reales Ordenanzas», en Reconquista, núm. 349, abril 1979, p. 46.

${ }^{171}$ En todas las profesiones y oficios, por humildes y simples que sean - significa el Equipo R («Vida, Servicio y Milicia», en Reconquista, núm. 373, junio 1981, pp. 10-11)-, se sirve a la sociedad, pero en la Milicia, en los Ejércitos, la idea de servicio ha de estar en lugar primordial en los pensamientos y sentimientos. De ahí esa famosa expresión que figura, en la entrada principal, en la fachada de cualquier centro militar: «Todo por la Patria».

Por su lado, García Escudero (en «La misión del militar», en Reconquista, núm. 394, mayo 1983, p. 57) ha puesto de relieve que son dos los aspectos cardinales de la vocación militar: la necesidad de afrontar la guerra y el ejercicio del mando. Pues bien, junto a estos dos conceptos se encuentran siempre latentes los dos contraconceptos que contrarrestan y dan sentido y justificación a aquéllos: la paz, en nombre de la cual únicamente se puede afrontar la guerra, y el servicio, en atención al cual y solamente así se tiene el perfecto derecho a mandar.

Incluso se ha señalado (Francisco LAGUNA SANQUiRICo, «El espíritu de servicio», en Reconquista, núm. 348, marzo 1979, p. 16) que la misma actitud disciplinada del militar no procede de una postura mecanicista o falta de personalidad, como tampoco tiene el mismo origen que la obediencia monacal, sino que se apoya en el servicio.

172 Francisco Laguna Sanquirico, «El espíritu de servicio», op. cit.

${ }_{173}$ Puede verse este discurso del Rey en Reconquista, núm. 380, febrero 1982, pp. 5-7. 
munidad ocupa un lugar destacado dentro del código moral de la institución armada, asumiéndolo sus miembros a título de honor.

La consecuencia inmediata de todo ello, como fácilmente se colige, es la existencia de una auténtica unión espiritual entre el pueblo y sus Ejércitos; sin ella, la vocación de servicio se convertirá en un fin puramente teórico, abstracto, pero de difícil verificación empírica; y para que esa unión sea posible, requisito previo insoslayable habrá de ser la integración social de los Ejércitos.

Esa identidad no es, en principio, difícil de conseguir, pues las FAS son una parte del pueblo; son la parte del pueblo en armas, jerarquizada y disciplinada, que tiene su razón de ser precisamente en la defensa de su pueblo ${ }^{174}$, o, como también se las ha considerado ${ }^{175}$, son el sector militar de la sociedad.

Ahora bien, la identidad o unión espiritual antes referida debe entenderse en un sentido que trascienda el hecho incuestionable de que Ejércitos y pueblo son una misma cosa; negar tal circunstancia implicaría admitir que constituyen un cuerpo extraño enquistado en la sociedad; de ahí que el verdadero y profundo sentido de esa unión sea que ambos, sociedad y comunidad militar, piensan y marchan al unísono ${ }^{176}$, que entre la sociedad y la comunidad castrense se ha establecido una mutua corriente de identificación, merced tanto a la incorporación a los Ejércitos de los anhelos y expectativas de la comunidad nacional, prueba de su inserción rigurosa en la misma, como también a la aceptación unánime por parte de la sociedad de la idiosincrasia y peculiaridades de la institución militar ${ }^{177}$.

Sólo a través de esa simbiosis tendrá sentido y viabilidad la misión última y a la vez más trascendente de los Ejércitos: garantizar la continuidad de la acción histórica de una comunidad, protegiendo sus valores y su identidad ${ }^{178}$.

\section{El progresivo ensamblaje Ejércitos-sociedad}

Las relaciones de todo ser humano con el mundo circundante tienden a caracterizarse por la apertura hacia los demás. Y si esto es una realidad, imprescindible por lo demás, a nivel individual, con más motivo aún lo debe ser a nivel social. Como se ha puesto de relieve ${ }^{179}$, a nivel de colectividades se hacen necesarios un estrecho contacto y una mutua valoración entre los esta-

${ }^{174}$ Así consideraría a las FAS el ministro de Defensa, señor Oliart Saussol, en su discurso con motivo de la Pascua Militar de 1982.

${ }^{175}$ Miguel Alonso BaQUer, «Tres esferas de actividad», en Reconquista, núm. 389, diciembre 1982 , p. 38 .

${ }_{176}$ En análogo sentido se pronuncia Francisco López DE SEPúlvedA, «Sociedad y Fuerzas Armadas (I)», op. cit., p. 13.

${ }^{177}$ Hilario Martín Jrménez, Los valores morales de las Fuerzas Armadas en las Reales Ordenanzas de S. M. don Juan Carlos 1, op. cit., p. 38.

${ }_{178}$ José M. ${ }^{2}$ García Escudero, «La profesionalidad», en Reconquista, núm. 394, mayo 1983, p. 56.

${ }_{179}$ Prudencio García, Eiército: presente y futuro, op. cit., p. 234. 
mentos civiles y militares. Ni la sociedad civil puede desvincularse de los problemas ligados a la defensa (bien que, de modo inevitable, esta desvinculación tienda a acentuarse en los largos períodos de paz) ni tampoco las Fuerzas Armadas pueden, so pretexto de erigirse en depositarias de unos valores permanentes, encerrarse, como dirá Close ${ }^{180}$, en una situación de separación en la cual el Ejército se mantiene cuidadosa y prudentemente desviado de las grandes corrientes constitutivas de nuestro tiempo.

$\mathrm{Y}$, en este orden de consideraciones, a nuestro modo de ver, no es válido ya el rechazo del aislamiento social del oficial para, a renglón seguido, significar ${ }^{181}$ que lo que en realidad ocurre es que en su esquema de valores predomina lo permanente sobre lo accidental, la cautela sobre la ligereza, la evolución ponderada frente a las rupturas violentas, y ello aun cuando pueda estarse más o menos conforme con la realidad de estas afirmaciones. Es evidente que existen una serie de valores que a lo largo del tiempo se mantienen estables; su sedimentación inspira tradiciones de notoria raigambre militar; como nos recuerda Riaza ${ }^{182}$, la institución militar tiene unas peculiaridades que es preciso tener en cuenta al definir su identidad; en todo ejército existe una propensión a encarnar en unas «glorias históricas» los valores mitificados en que se inspira, materializados en unos símbolos y personificados por unos héroes. El cultivo del patriotismo debe ser tenido muy en cuenta por la sociedad civil a la hora de comprender "por dentro» a la institución castrense.

Se hace necesario, pues, una aproximación a la profesión militar, realizada sobre las bases de la mutua comprensión y respeto; es ésta una exigencia incluso del buen funcionamiento de nuestra sociedad, y para su realización requiere, como se ha advertido ${ }^{183}$, un conocimiento de las instituciones armadas que hasta el momento presente no puede decirse que exista.

Pero, al unísono, es imprescindible - como significa Prudencio García ${ }^{184}$ una evolución de la mentalidad militar y de su ámbito de responsabilidades morales. En la hora presente, no existe profesión seriamente implicada en el campo de los comportamientos sociales que no se halle en trance de profunda autorrevisión moral de sus misiones, funciones y responsabilidad frente a sí mismo y frente a la comunidad global en la que se inserta, de la que vive y a la que sirve. Pretender que la profesión armada -una de las que contrae sobre sus hombros más numerosos, complejos y graves compromi-

${ }^{180}$ Coronel Robert Ch. Close, «La educación política en las Fuerzas Armadas», en Revue Militaire Générale, reproducido por la revista Ejército, núm. 396. Cit. por Prudencio García, op. cit., p. 234.

${ }_{181}$ Tal es, por ejemplo, el posicionamiento de Antonio Sánchez Sánchez-Serrano, «Humanismo y Fuerzas Armadas», en Boletín de Información CESEDEN, núm. 181-X, marzo 1985 , p. 17.

${ }_{182}$ José M. ${ }^{a}$ Riaza Ballesteros, Lineas generales de la reforma de la enseñanza militar, op. cit., p. 6.

${ }^{183}$ Fernando Fernández Bastarreche, El Ejército español en el siglo XIX, Siglo XXI de España Editores, Madrid, 1978, p. 3.

${ }_{184}$ Cfr., al efecto, Prudencio García, Ejército: presente y futuro, op. cit., pp. 172 y ss. 
sos morales de toda índole - pueda constituir una excepción a esta general necesidad introspectiva, estando libre per se de someterse nunca a este tipo de autoanálisis, supondría atribuirle un puro carácter extraterráqueo ${ }^{185}$.

Es obvio que los Ejércitos no pueden permanecer asépticamente encerrados en una hermética cápsula aislante, inmersa en un mundo pleno de tensiones. Bien al contrario, los Ejércitos del futuro deben ir tomando conciencia, a través de un progresivo proceso de intelectualización política y humana, de que en el posible - más aún, obligado - tránsito hacia un mundo sin guerras habrán de cargar sobre sus hombros con una importante fracción de una responsabilidad general compartida en defensa de unos valores e intereses comunitarios de alcance no nacional ni de bloque, sino universal, valores que no pueden ser otros que los de una paz generalizada y definitiva en un mundo humanizado y dignamente habitable ${ }^{186}$.

Al margen ya de estas reflexiones, que plantean la necesidad real, desde una perspectiva ético-moral, de una mutación en la mentalidad militar, de una apertura de la misma a las preocupaciones y valores de la sociedad que le sirve de marco, cabe recordar que, como ya hemos ido analizando a lo largo de las páginas que preceden, una serie dispar de circunstancias ha ido relativizando el influjo de alguno de los factores otrora orientados a potenciar el aislamiento social de la institución castrense; más aún, en algún caso, la realidad imperante ha transmutado el signo de alguno de esos factores, que se han convertido, o están en trance de hacerlo, en potenciadores de esa necesaria simbiosis Ejércitos-sociedad.

Los cambios en el reclutamiento de la oficialidad, a los que se refiere Janowitz ${ }^{187}$, han propiciado que las Fuerzas Armadas estén integradas por una más amplia base social, con mayor representatividad, por tanto, del conjunto de la población.

De otro lado, las nuevas formas de la guerra, y en especial esa idea envolvente de la guerra total, qué duda cabe que han propiciado un acercamiento entre la sociedad y sus Ejércitos ${ }^{188}$; no en vano la movilización masiva de ciudadanos y el carácter generalizado del enfrentamiento colocan a militares y civiles en una situación de amenaza equivalente. La guerra total sumerge a todos los miembros de la sociedad bajo el mismo peligro de destrucción completa.

Los avances tecnológicos también inciden en la cuestión que nos ocupa. De un lado, implican una cada vez más íntima relación entre sociedad civil y corporación militar; no en vano los avances científicos suelen en muchos casos tener una vertiente militar y, a la inversa, la tecnología bélica entraña en

185 Ibidem, p. 177

${ }^{186}$ Ibidem, pp. 174-175.

${ }_{187}$ Morris JANowitz, The Protessional Soldier..., op. cit., p. 10.

${ }_{188}$ En análogo sentido se pronuncian Rafael BAÑón y José A. Olmeda, «El estudio de las Fuerzas Armadas», en Bañón y Olmeda (comps.), La Institución militar..., op. cit., pp. 13 y ss.; en concreto, p. 48. 
ocasiones un aporte de interés para la industria no militar. De otro lado, el profesional de las armas viene obligado a un conocimiento técnico cada vez más profundo, con lo que, como asimismo significara Janowitz ${ }^{189}$, disminuyen las diferencias entre los conocimientos y saberes de militares y civiles, todo lo cual, a su vez, propicia unas civilianizing tendencies a las que ya hemos aludido en otra ocasión.

Junto a todo lo expuesto, no podemos olvidar el progresivo desarrollo, desde hace ya muchos lustros, de una cada vez más compleja burocracia militar ${ }^{190}$. Tan es así que el mismo Ortega y Gasset definiría al militar como «el guerrero deformado por el industrialismo». Algún tiempo más tarde, en $E l$ Espectador, escribiría Ortega: «Una cosa es el guerrero y otra el militar. La Edad Media desconoció el militarismo. El militar significó la degeneración del guerrero, corrompido por el industrial. El militar es un industrial armado, un burócrata que ha inventado la pólvora» ${ }^{191}$. Y Morris Janowitz, con relación a la institución armada, la considerará - a primera vista- como una vasta organización para las operaciones técnicas y logísticas, en la que una parte preponderante de sus integrantes está comprometida en funciones administrativas ${ }^{192}$.

En todo caso, la burocratización del instituto armado parece claro que incide positivamente al logro de una más estrecha relación entre las Fuerzas Armadas y la sociedad en que se imbrican ${ }^{193}$. Las FAS — se ha advertido ${ }^{194}$ son primordialmente logística y administración; crece paulatinamente el número y complejidad de los medios necesarios para poner un soldado en situación de combate. Asimismo, se incrementan las misiones «político-militares» que tienen que desempeñar los oficiales. Los Ejércitos se civilinizan por el tipo de actuaciones que realizan y los conocimientos que recogen orgánicamente. $\mathrm{Y}$ en semejante dirección se pronuncian Moskos y Harries-Jenkins ${ }^{195}$ cuando ponen de relieve que el tradicional papel del guerrero heroico ha

${ }^{189}$ Morris Janowitz, The Professional Soldier..., op. cit., p. 9.

190 Acerca de la burocratización de las Fuerzas Armadas pueden verse, entre otros, Maury D. Feld, The Structure of Violence. Armed Forces as Social Systems, Sage Publications, Beverly Hills (Calif.), 1977; Jacques van Doorn, «The Officer Corps: a fusion of profession and organization», en European Archives of Sociology, 6, 1975, pp. 262 y ss.; Arthur K. Davies, «Bureaucratic patterns in the navy officer corps», op. cit.; es de gran interés, asimismo, el tratamiento que del tema hace Max WEBER en Economy and Society, Bedminster Press, Nueva York, 1968.

191 Cit. por José Ma Gárate, Los intelectuales y la Milicia, Servicio de Publicaciones del EME, Madrid, 1983, p. 341.

${ }_{192}$ Morris JanOWITZ y Roger W. LITTLE, Sociology and the Military Establishment,

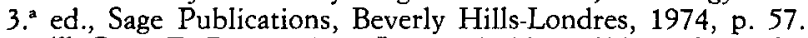

${ }_{193}$ Gene E. BIGLER (en «La restricción política y la profesionalización militar en Venezuela», op. cit., p. 104) señala al efecto que el desarrollo de una burocracia militar con oficiales profesionales de carrera, y su propia racionalidad organizativa, tuvo consecuencias importantes para el total involucramiento de los militares en la sociedad venezolana.

194 Rafael Bañón y José Antonio Olmeda, «El estudio de las Fuerzas Armadas», op. cit., p. 50.

${ }_{195}$ Gwyn Harries-Jenkins y Charles C. Moskos, Jr., Las Fuerzas Armadas y la Sociedad, op. cit., p. 52. 
dado paso a una función directivo-administrativa; en suma, la profesión militar en su totalidad ha adquirido cierta semejanza con las grandes instituciones burocráticas de carácter no militar. El Ejército se ha civilinizado.

En definitiva, en nuestros días numerosas variables están incidiendo en las relaciones Fuerzas Armadas-sociedad en el sentido de forzar la ruptura del tradicional aislamiento social de la comunidad castrense, a todas luces perjudicial para ésta y para la misma sociedad; creemos que se está en vías de ello, para lo cual, desde luego, es necesaria la colaboración de las dos partes implicadas. Quisiéramos terminar haciendo nuestras las consideraciones de un miembro de la comunidad militar que, desde la óptica de la institución castrense, y tras decantarse por la necesidad de extremar el cuidado con el fin de superar el peligro que supone la desvinculación sociedad-Fuerzas Armadas, manifiesta lo que sigue: "Vincularse a la sociedad significa, en primer lugar, ser respetuoso con ella por más que se esté en desacuerdo con algunas de las facetas que presenta. En segundo lugar, no encerrarse en un baluarte, sino practicar una defensa móvil. En tercero, no dividir de forma tajante a la sociedad en "buenos y malos", en amigos incondicionales y enemigos irreconciliables. De entrada, las virtudes y los defectos suelen anidar en todos los árboles y la apreciación del saldo entre unas y otros acostumbra a ser subjetiva» ${ }^{19}$. Sólo puntualizaríamos que, para nosotros, esa «defensa móvil» a que alude el autor anterior no puede entenderse sino como una actitud abierta por mor de la cual los miembros de la profesión, a la par que están dispuestos a defender aquellos valores tradicionales que estiman ínsitos en la esencia de la misma, se encuentran decididos a asumir como propios los nuevos valores que la sociedad en su conjunto ha hecho suyos; sólo una actitud o predisposición de esta naturaleza hará factible la integración sociedad-FAS.

${ }^{196}$ Francisco López DE SEPúlvedA, «Sociedad y Fuerzas Armadas» (II), op. cit., p. 23. 